\title{
Cannabidiol directly targets mitochondria and disturbs calcium homeostasis in acute lymphoblastic leukemia
}

\author{
Miguel Olivas-Aguirre (i]', Liliana Torres-López', Juan Salvador Valle-Reyes', Arturo Hernández-Cruz², \\ Igor Pottosin (1) and Oxana Dobrovinskaya (1)
}

\begin{abstract}
Anticancer properties of non-psychoactive cannabinoid cannabidiol (CBD) have been demonstrated on tumors of different histogenesis. Different molecular targets for CBD were proposed, including cannabinoid receptors and some plasma membrane ion channels. Here we have shown that cell lines derived from acute lymphoblastic leukemia of $\mathrm{T}$ lineage (T-ALL), but not resting healthy T cells, are highly sensitive to CBD treatment. CBD effect does not depend on cannabinoid receptors or plasma membrane $\mathrm{Ca}^{2+}$-permeable channels. Instead, CBD directly targets mitochondria and alters their capacity to handle $\mathrm{Ca}^{2+}$. At lethal concentrations, CBD causes mitochondrial $\mathrm{Ca}^{2+}$ overload, stable mitochondrial transition pore formation and cell death. Our results suggest that CBD is an attractive candidate to be included into chemotherapeutic protocols for T-ALL treatment.
\end{abstract}

\section{Introduction}

Acute lymphoblastic leukemia (ALL) of T lineage (TALL) represents a highly aggressive cancer, resistant to chemotherapy and with increased risk of relapse, which occurs in $15 \%$ of childhood and $25 \%$ of adult ALL cases. In T-ALL, a long-term remission fails in $\sim 20 \%$ of children and $40 \%$ of adult patients. The prognosis for these groups remains poor, with a 5 -year survival rate of $<25 \%{ }^{1-5}$. Thus, novel therapeutic strategies for the T-ALL treatment are needed.

Cannabinoids are a group of more than 60 structurally related terpenophenolic compounds. Most of them exert their effects through cannabinoid CB1 and CB2 receptors, which belong to the family of $G$ protein-coupled

\footnotetext{
Correspondence: Igor Pottosin (pottosin@ucol.mx) or

Oxana Dobrovinskaya (oxana@ucol.mx)

'Laboratory of Immunobiology and Ionic Transport Regulation, University Center for Biomedical Research, University of Colima, Av. 25 de Julio 965, Col. 28030 Colima, Mexico

${ }^{2}$ Department of Cognitive Neuroscience and National Laboratory of

Channelopathies (LaNCa), Institute of Cellular Physiology, National

Autonomous University of Mexico, Mexico-City, Mexico

Edited by M. Diederich
}

receptors. Lymphocytes mainly express $\mathrm{CB} 2$, whereas $\mathrm{CB} 1$ are highly expressed in the central nervous system (CNS). Cannabinoids have been used for decades in the field of palliative care. Recently two phytocannabinoids, $\Delta^{9}$-tetrahydrocannabinol (THC) and cannabidiol (CBD), were found to possess antitumorigenic properties ${ }^{6,7}$. Contrary to $\mathrm{THC}$, a well-known strong CB1 agonist with psychotropic effect, CBD has a low binding affinity for CB1/2 receptors and is considered as a "non-intoxicating drug"8. Molecular targets for CBD are uncertain. Among putative candidates, some members of the TRP channels' family, orphan cannabinoid receptor GPR55, 5HT and PPAR $\gamma$ receptors have been proposed ${ }^{6,9}$.

In the present study we addressed the immediate targets for CBD in leukemic cell lines, derived from T-ALL patients in relapse.

\section{Results}

CBD suppresses viability and impairs migration of leukemic T cells

Cytotoxic effect of CBD was first evaluated in leukemic cell lines of different lineages, including T-ALL, B lineage-

\section{(c) The Author(s) 2019}

(c) (i) Open Access This article is licensed under a Creative Commons Attribution 4.0 International License, which permits use, sharing, adaptation, distribution and reproduction c. in any medium or format, as long as you give appropriate credit to the original author(s) and the source, provide a link to the Creative Commons license, and indicate if changes were made. The images or other third party material in this article are included in the article's Creative Commons license, unless indicated otherwise in a credit line to the material. If material is not included in the article's Creative Commons license and your intended use is not permitted by statutory regulation or exceeds the permitted use, you will need to obtain permission directly from the copyright holder. To view a copy of this license, visit http://creativecommons.org/licenses/by/4.0/. 
derived ALL (B-ALL), and chronic myelogenous leukemia (CML) by means of metabolic assay. T-ALL were the most CBD-sensitive among tested cell lines (Fig. 1a). However, there is an uncertainty in the interpretation of this result, which may be explained by mitochondrial metabolism inhibition, decreased proliferation rate, increased level of cell death, or combination of these effects. Then survival and proliferation of CBD- treated Jurkat cells were evaluated in long-lasting $(72 \mathrm{~h})$ cultures by counting live and dead cells CBD at $30-100 \mu \mathrm{M}$ induced cell death, while at $10 \mu \mathrm{M}$ the cells remained alive, but did not proliferate. Noteworthy, at low $(1 \mu \mathrm{M})$ concentration, CBD stimulated the cell proliferation (Fig. 1b, left). Stimulation was also obtained in experiments with a sequential $(1 \mu \mathrm{M}$ every $24 \mathrm{~h}) \mathrm{CBD}$ administration (Fig. $1 \mathrm{~b}$, right). Strikingly, dose dependence was very similar in both cases, irrespective to supposed CBD accumulation during sequential application. Apparently, cell fate was defined already by the first CBD administration.

In additional experiments, cervical and breast cancer cell lines were included for a comparison, because CBD effect on these types of cancer was reported earlier. Again, among 10 cell lines tested, cytotoxic effect of CBD was the most pronounced in T-ALL (Fig. 1c).

We also tested CBD toxicity in non-tumoral cells. Murine bone marrow-derived cell line OP9 displayed high resistance to CBD (Fig. 1d). Strikingly, in contrast to activated human $\mathrm{CD} 4^{+} \mathrm{T}$ cells, resting $\mathrm{CD} 4^{+} \mathrm{T}$ cells were relatively insensitive to $\mathrm{CBD}$. Noteworthy, resting $\mathrm{CD} 4^{+}$ $\mathrm{T}$ cells pretreated with $\mathrm{CBD}(30 \mu \mathrm{M}, 24 \mathrm{~h})$ were able to respond to activating stimuli. At $72 \mathrm{~h}$ of activation their proliferative response was statistically indistinguishable from that of untreated $\mathrm{CD} 4^{+}$cells (Fig. 1e).

The infiltration of lymph nodes and CNS by leukemic cells and formation of a mediastinal mass are tightly related to disease relapse and unfavorable prognosis in $\mathrm{T}$ $\mathrm{ALL}^{10}$. Thus, the effect of CBD on the T-ALL cells migration was addressed. Since CXCL12/CXCR4 axis plays a significant role in the dissemination of leukemic cells $^{11,12}$, CXCL12 was used as a chemoattractant. Migration of T-ALL cells was shown to be significantly suppressed by $2 \mathrm{~h}$ preincubation with $30 \mu \mathrm{M} \mathrm{CBD}$ (Fig. 1f).

CBD $(30-100 \mu \mathrm{M})$ triggered apoptosis in a part of the cell population (Annexin V - single positive cells). At the same time, loss of plasma membrane integrity was observed in a large cell population as early as at $4 \mathrm{~h}$ of treatment (Annexin V/ propidium iodide (PI) - double positive cells), indicating necrosis (Fig. $1 \mathrm{~g}-\mathrm{i}$ ).

Transmission electron microscopy (TEM) imaging revealed multiple dramatic changes in cell morphology already after $2 \mathrm{~h}$ of CBD $(30 \mu \mathrm{M})$ exposure (Fig. 2). Two of the most characteristic features were extensive cytoplasmic vacuolation and numerous swollen mitochondria, devoid of cristae. Golgi complex and endoplasmic reticulum (ER) were disassembled, which seems to be related to cytoplasmic vacuolation. Plasma membrane blebbing and apoptotic bodies (ApoBDs) formation were detected. The observed morphological changes pointed out to a complex mechanism, with both apoptotic and necrotic symptoms. In addition, double membrane vacuoles, containing degrading material (autophagosomes), were much more numerous in CBD-treated cells as compared to control.

\section{Sublethal CBD concentrations activate autophagy in leukemic cells}

Autophagy is a catabolic cellular process, representing an important strategy to ensure cell homeostasis by the elimination of defunct organelles in both physiological and pathological conditions ${ }^{13}$. Basal levels of autophagy serve a housekeeping function, whereas stress stimulates autophagy. CBD was shown to cause cell death by inducing a crosstalk between apoptosis and autophagy in breast cancer ${ }^{14}$. To reveal the ability of CBD to induce autophagy in T-ALL, LC3-I to LC3-II conversion and LC3-II turnover were monitored by immunoblotting. In the course of autophagy, microtubule-associated protein LC3-I first conjugates with phosphatidylethanolamine, forming LC3-II, followed by the LC3-II translocation to autophagosomes. An increased LC3-II level is considered as an indicator of the autophagy, but LC3-II is degraded by lysosomal proteases after autophagosome-lysosome fusion. Chloroquine (CQ) is known to prevent autophagosome-lysosome fusion and to inhibit the LC3-II degradation, thus LC3-II is accumulated in the presence of $\mathrm{CQ}^{15,16}$. Western blot analysis of LC3 variants demonstrated that sublethal CBD concentration $(10 \mu \mathrm{M})$ effectively induced autophagy in Jurkat cells (Fig. 3a, b), since LC3-II level was higher in cells treated with both CBD $(10 \mu \mathrm{M})$ and CQ $(20 \mu \mathrm{M})$ when compared to either $20 \mu \mathrm{M}$ CQ (basal autophagy) or $10 \mu \mathrm{M}$ CBD treatment alone. Note that accumulation of LC3-II was diminished by its degradation during the autophagic flux in the samples without $C Q$.

Proceeding of the autophagic flux at the single-cell level was monitored using mCherry-GFP-LC3 expressing Jurkat cells. The mCherry-GFP-LC3 experimental strategy is based on the fact that GFP is quenched at acidic $\mathrm{pH}$, found in the autophagolysosome, while mCherry is not. Accordingly, enhancement of the mCherry/GFP ratio sensitive to CQ indicates the autophagolysosome formation ${ }^{17}$. Figure $3 \mathrm{c}$ shows representative images from the experiment, in which Jurkat GFP-mCherry-LC3 cells were incubated with CBD (10 and $30 \mu \mathrm{M})$ and $C Q$, alone or in combination. High mCherry/GFP ratio, efficiently equalized by $C Q$, was observed in samples, treated with $10 \mu \mathrm{M}$ CBD (Fig. 3d, e), evidencing a throughput of the autophagic pathway. In samples treated with $30 \mu \mathrm{M}$ CBD this 


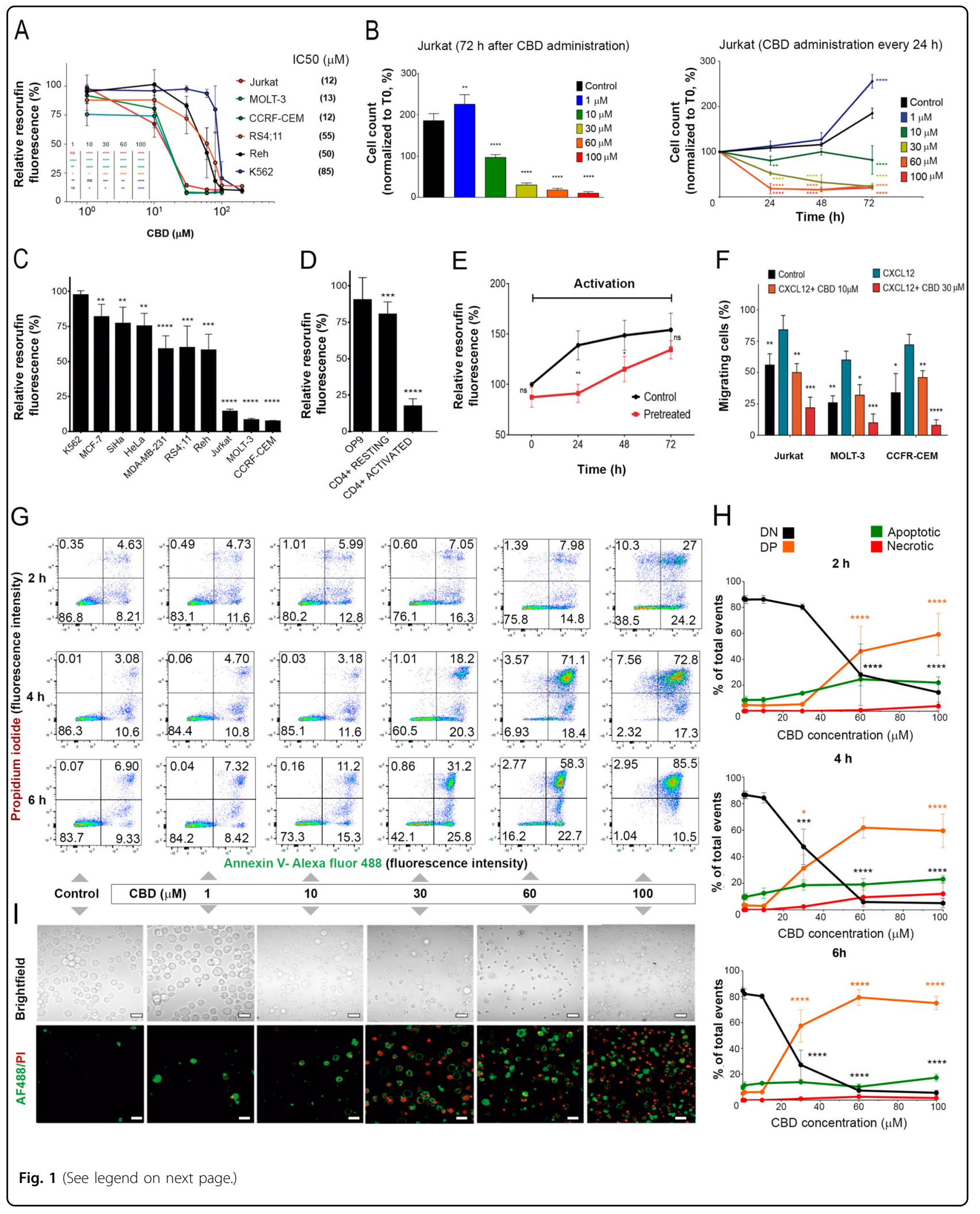


(see figure on previous page)

Fig. 1 CBD effect on viability in different cancer cell lines. a Cell viability, evaluated by resazurin-based metabolic assay, as a function of CBD concentration in human leukemic cell lines of different lineages at $24 \mathrm{~h}$ of treatment. Cell lines derived from T-ALL (Jurkat, MOLT-3, and CEM), B-ALL (RS4;11 and Reh) and CML (K562) were tested. Data (resorufin fluorescence intensity, arbitrary units) were normalized to the vehicle-treated control and shown as mean $\pm \mathrm{SD}\left(n=8 ;{ }^{*} p<0.05 ;{ }^{* *} p<0.01 ;{ }^{* * *} p<0.001 ;{ }^{* * *} p<0.0001 ;\right.$ ns, not significant; one-way ANOVA). b Live cell count (trypan blue exclusion test) in long-lasting Jurkat cells cultures exposed to different CBD concentrations (0-100 $\mu \mathrm{M})$. Left: cell count at $72 \mathrm{~h}$ after single CBD administration; right: fresh CBD was added, 50\% of medium volume was changed and cells were counted every $24 \mathrm{~h}$. Data are normalized to the initial point $(0 \mathrm{~h})$ and shown as mean $\pm \mathrm{SD}\left(n=3 ;{ }^{* *} p<0.01 ;{ }^{* *} p<0.001 ;{ }^{* * *} p<0.0001\right.$, one-way ANOVA test). c Cell viability was evaluated by resazurin-based metabolic assay at $24 \mathrm{~h}$ of treatment with $\mathrm{CBD}(30 \mu \mathrm{M})$ in human tumor cell lines of different histogenesis, including CML (K562), BALL (Reh and RS4;11), T-ALL (CEM, MOLT-3, and Jurkat), cervical cancer (SiHa and HeLa), and breast cancer (MCF7-7 and MDA-MB-231). Data (resorufin fluorescence intensity) were normalized to vehicle-treated control and reported as mean $\pm \mathrm{SD}\left(n=8\right.$ of four independent experiments; ${ }^{*} p<0.05$; ${ }^{* *} p<0.01 ;{ }^{* *} p<0.001 ;{ }^{* * *} p<0.0001$, Student's t-test). $\mathbf{d}$ Cell viability was evaluated by resazurin-based metabolic assay at $24 \mathrm{~h}$ of treatment with CBD $(30 \mu \mathrm{M})$ in non-cancerous cells. Human CD4 ${ }^{+}$cells were activated with anti-CD3/CD28 antibodies as described in Materials and Methods section. Data (resorufin fluorescence intensity) are normalized to the vehicle-treated control and reported as mean \pm SD ( $n=8$ in at least three independent experiments; ${ }^{*} p<0.05 ;{ }^{* *} p<0.01$; ${ }^{* *} p<0.001 ;{ }^{* * *} p<0.0001$; Student's $t$-test). e After preincubation with CBD (30 $\left.\mu \mathrm{M}, 24 \mathrm{~h}\right)$, non-cancerous CD4 ${ }^{+}$ cells were activated by anti-CD3/antiCD28 antibodies. Cell viability was evaluated by resazurin-based metabolic assay every $24 \mathrm{~h}$. Data (resorufin fluorescence intensity) were normalized to $0 \mathrm{~h}$ time point and shown as mean $\pm \mathrm{SD}$ ( $n=8$ in at least three independent experiments). Statistical comparison between control and pretreated samples was undertaken at each time point $\left({ }^{*} p<0.05 ;{ }^{* *} p<0.01 ;{ }^{* * *} p<0.001 ;{ }^{* * *} p<0.0001\right.$, Student's $t$-test). $\mathbf{f}$ Migration capacity of Jurkat cells pretreated with CBD (10 or $30 \mu \mathrm{M}, 2 \mathrm{~h}$ ) was evaluated by chemotactic migration assay, using a Transwell system. Cells were allowed to migrate for $4 \mathrm{~h}, \mathrm{CXCL} 12$ was used as a chemoattractant. The percentage of migrated cells was determined by cells count in the lower chamber. Data are mean $\pm \mathrm{SD}(n=4)$. Statistical comparison was made with respect to positive control $(C X C L 12)\left({ }^{*} p<0.05 ;{ }^{* *} p<\right.$ $0.01 ;{ }^{* * *} p<0.001 ;{ }^{* * *} p<0.0001$, one-way ANOVA test). $\mathbf{g}-\mathbf{i}$ Cell death was evaluation by flow cytometry $(\mathbf{g}, \mathbf{h})$ and fluorescent microscopy (I) in Jurkat cells treated with different concentrations of CBD using Annexin V-AF488/PI double staining. Representative dot plots $(2,4$, and $6 \mathrm{~h})$ and images (12 h) are shown in $\mathbf{g}$ and $\mathbf{i}$, correspondingly. Scale bar: $20 \mu \mathrm{m}$. In every dot plot lower left quadrant represents Annexin $\mathrm{V}^{-} \mathrm{PI}^{-}$(DN) live cells, in the lower right quadrant are Annexin $\mathrm{V}^{+} \mathrm{PI}^{-}$(early apoptotic) cells, Annexin $\mathrm{V}^{-} \mathrm{PI}{ }^{+}$(primary necrotic) cells are in the upper left quadrant, whereas the double-stained population Annexin $\mathrm{V}^{+} \mathrm{Pl}^{+}$(DP) in the upper right quadrant represents dead cells, which may include necrotic and late apoptotic ones. Statistical analysis of flow cytometry data is given in $\mathbf{h}\left(n=3 ;{ }^{*} p<0.05 ;{ }^{* *} p<0.01 ;{ }^{* * *} p<0.001 ;{ }^{* * *} p<0.0001\right.$, one-way ANOVA test)

ratio was low (Fig. 3d, e). However, the number of autophagosomes was increased at early times after CBD administration $(30 \mu \mathrm{M})$, as it was revealed by an enhanced level of both $\mathrm{GFP}^{+}$and mCherry ${ }^{+}$puncta (Fig. 3f, g). These data may be explained by a truncation of basal, and, possibly, also CBD-induced autophagy at late phases in damaged cells.

\section{CBD causes mitochondrial damage and induces cytochrome $\mathrm{C}$ release}

Dissipation of the mitochondrial transmembrane potential $(\Delta \Psi \mathrm{m})$ is a hallmark of the mitochondrial permeability transition (MPT) - driven necrosis as well as of intrinsic apoptosis. It involves an irreversible mitochondrial outer membrane permeabilization and a release of various pro-apoptotic factors, including cytochrome $\mathrm{C}$ (Cyt-C), to the cytosol. In the cytosol, Cyt-C contributes to the apoptosome formation, with a consequent activation of the initiator caspase 9, which cleaves and activates executioner caspases ${ }^{18}$.

We monitored $\Delta \Psi \mathrm{m}$ in Jurkat cells double-stained with green fluorescent dye MtGreen, which covalently binds to mitochondrial matrix proteins, and tetramethylrhodamine ethyl ester (TMRE), a cationic fluorescent dye that is readily sequestered by energized mitochondria (Fig. 4a). When exposed to CBD $(30 \mu \mathrm{M})$, the intensity of TMRE fluorescence, in contrast to that of MtGreen, was gradually decreased within the first 10 min of treatment, indicating a rapid $\Delta \Psi \mathrm{m}$ loss (Fig. 4a, Supplementary Movie 1). The loss of TMRE fluorescence was dose-dependent (Fig. 4b). To monitor Cyt-C release from mitochondria in a response to CBD treatment, Jurkat cells were transfected with EYFPCyt-C. In untreated cells, Cyt-C localization was restricted to mitochondria, as confirmed by punctate distribution of EYFP-Cyt-C staining and its colocalization with TMRE (Fig. 4c, d). After treatment with CBD $(30 \mu \mathrm{M})$, EYFP-Cyt$\mathrm{C}$ distribution in the cytoplasm of treated cells became more diffuse (Fig. 4e), indicating Cyt-C release from mitochondria, observed as early as within the first $20 \mathrm{~min}$ of treatment (Fig. 4f). Concomitantly, cell volume was significantly reduced, as it was previously reported for CBD-treated Jurkat cells by others ${ }^{19}$. Jurkat cells, exposed to CBD, exhibited an enhanced activity of caspases 9 and 3 , confirming the triggering of intrinsic apoptotic pathway (Fig. 4g).

Collapse of the $\Delta \Psi \mathrm{m}$ is frequently associated with the induction of the mitochondrial permeability transition pore (mPTP), a wide channel formed through inner and outer mitochondrial membranes. The formation of $\mathrm{MPTP}$ is potently blocked by cyclosporine A $(\mathrm{CsA})^{20}$. Two distinct mechanisms, leading to the $\mathrm{Cyt}-\mathrm{C}$ release from mitochondria were suggested: one is related to the MPTP and inhibited by CsA and another is Bax-dependent but CsA-insensitive ${ }^{21,22}$. In our experiments both CBDinduced phenomena, Cyt- $\mathrm{C}$ release from mitochondria and cell shrinkage were inhibited by CsA (Fig. 4h). mPTP opening is associated with the oxidative stress ${ }^{20}$. CBDinduced reactive oxygen species (ROS) overproduction 


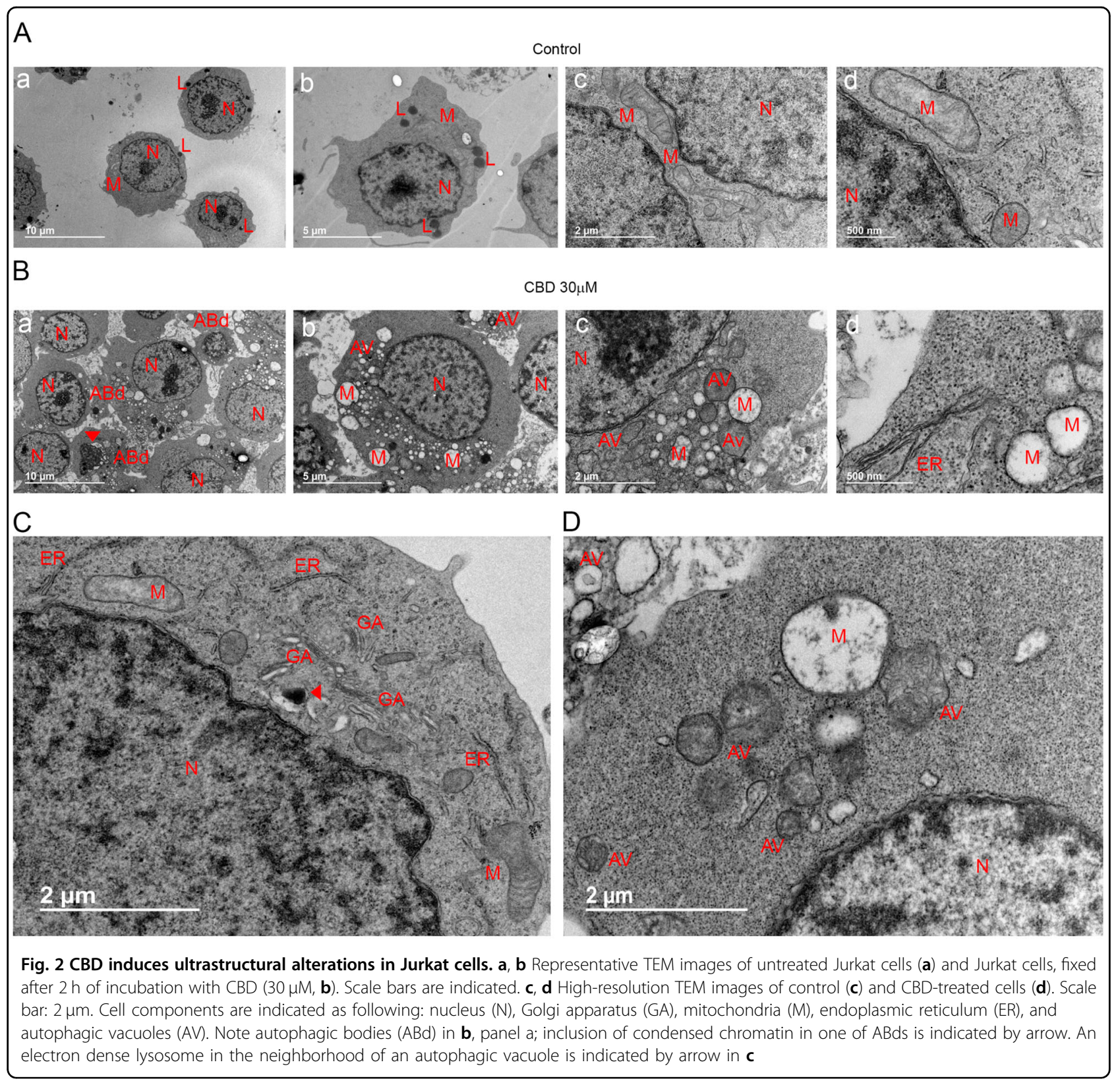

was previously reported in different cell models ${ }^{14,23}$. As shown in the Fig. 4i, CBD within few minutes provoked a dose-dependent increase in ROS generation.

\section{CBD-induced mitochondrial $\mathrm{Ca}^{2+}$ overload is responsible for the formation of MPTP}

CBD-mediated elevation of the cytosolic free $\mathrm{Ca}^{2+}\left(\left[\mathrm{Ca}^{2+}\right]_{\mathrm{i}}\right)$ has been observed in several cancer and non-cancerous cells ${ }^{24,25}$. Calcium signal signature defines the cell fate, survival, or death scenarios ${ }^{26}$. Elevated intramitochondrial $\mathrm{Ca}^{2+}\left(\left[\mathrm{Ca}^{2+}\right]_{\mathrm{m}}\right)$ is a prerequisite for the mPTP formation ${ }^{20}$. It is generally assumed that $\left[\mathrm{Ca}^{2+}\right]_{\mathrm{m}}$ increase is triggered by an increase of $\left[\mathrm{Ca}^{2+}\right]_{\mathrm{i}}$. In many cases, $\mathrm{Ca}^{2+}$ source can be ER, whose membranes come to a very close proximity with the outer mitochondrial membrane $(\mathrm{OMM})^{27}$.

CBD promoted a dose-dependent elevation of $\left[\mathrm{Ca}^{2+}\right]_{\mathrm{i}}$ from the resting level of $100 \mathrm{nM}$ up to $300 \mathrm{nM}$, both in TALL cells (Fig. 5a-d) and in healthy lymphocytes (Fig. 5e, f). Pharmacological analysis revealed that neither CB1/2 nor GPR55 receptors were involved in the CBDinduced $\left[\mathrm{Ca}^{2+}\right]_{\mathrm{i}}$ rise. Importantly, CBD-induced $\left[\mathrm{Ca}^{2+}\right]_{\mathrm{i}}$ rise was neither dependent on $\mathrm{Ca}^{2+}$ permeable channels in plasma membrane nor on extracellular $\mathrm{Ca}^{2+}$ (Fig. 5g-j). Thus, the source of $\mathrm{CBD}$-induced $\left[\mathrm{Ca}^{2+}\right]_{i}$ rise were intracellular $\mathrm{Ca}^{2+}$ stores. Blockage of plasma membrane 


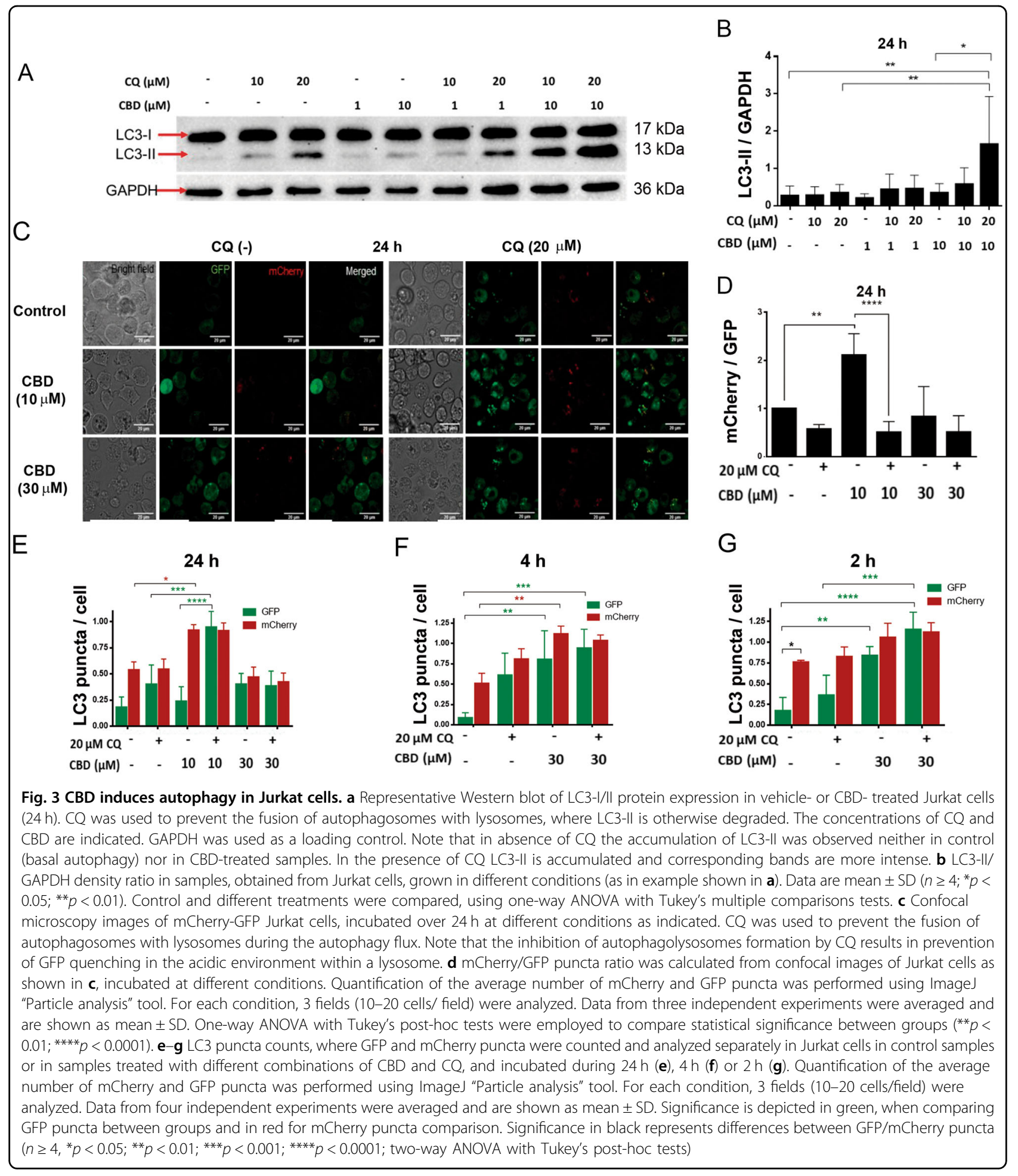

$\mathrm{Ca}^{2+}$ permeable channels by $\mathrm{Gd}^{3+}$ and ruthenium red (RR) did not protect leukemic cells against CBD (Fig. 5i, j).

To monitor $\left[\mathrm{Ca}^{2+}\right]_{\mathrm{m}}$, Jurkat cells were transfected with a $\mathrm{Ca}^{2+}$-sensitive, mitochondrial targeted indicator CEPIA3mt $(\mathrm{Kd}=11 \mu \mathrm{M})^{28}$. Specific mitochondrial targeting of
CEPIA3mt was confirmed by its colocalization with TMRE (Fig. 6a). Concurrent measurement of $\left[\mathrm{Ca}^{2+}\right]_{i}$ were conducted with cells loaded with a conventional cytosolic ratiometric dye Fura-2. CBD-induced $\left[\mathrm{Ca}^{2+}\right]_{\mathrm{i}}$ increase was preceded by $\left[\mathrm{Ca}^{2+}\right]_{\mathrm{m}}$ transient (Fig. 6b). Peak value for 


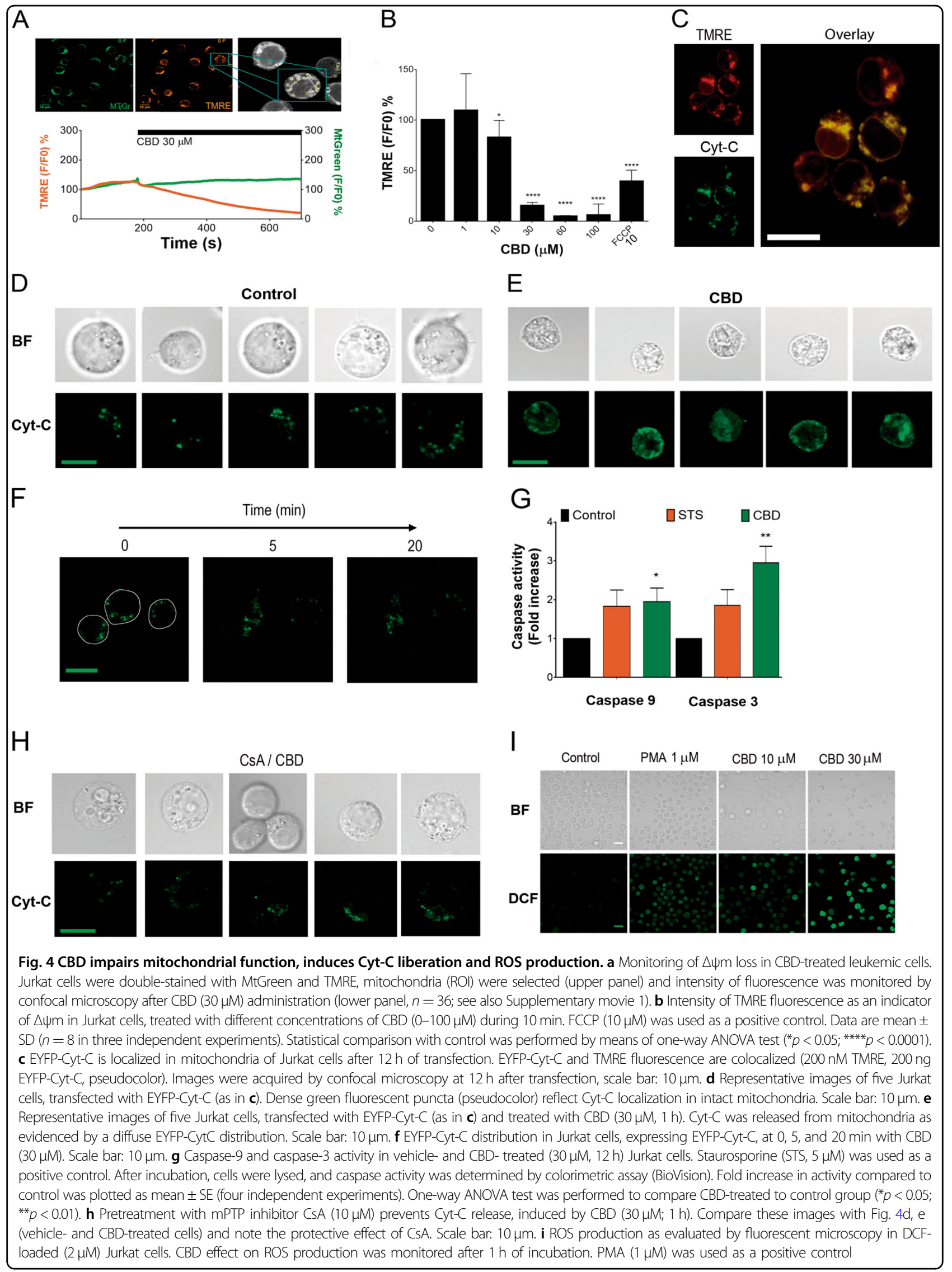




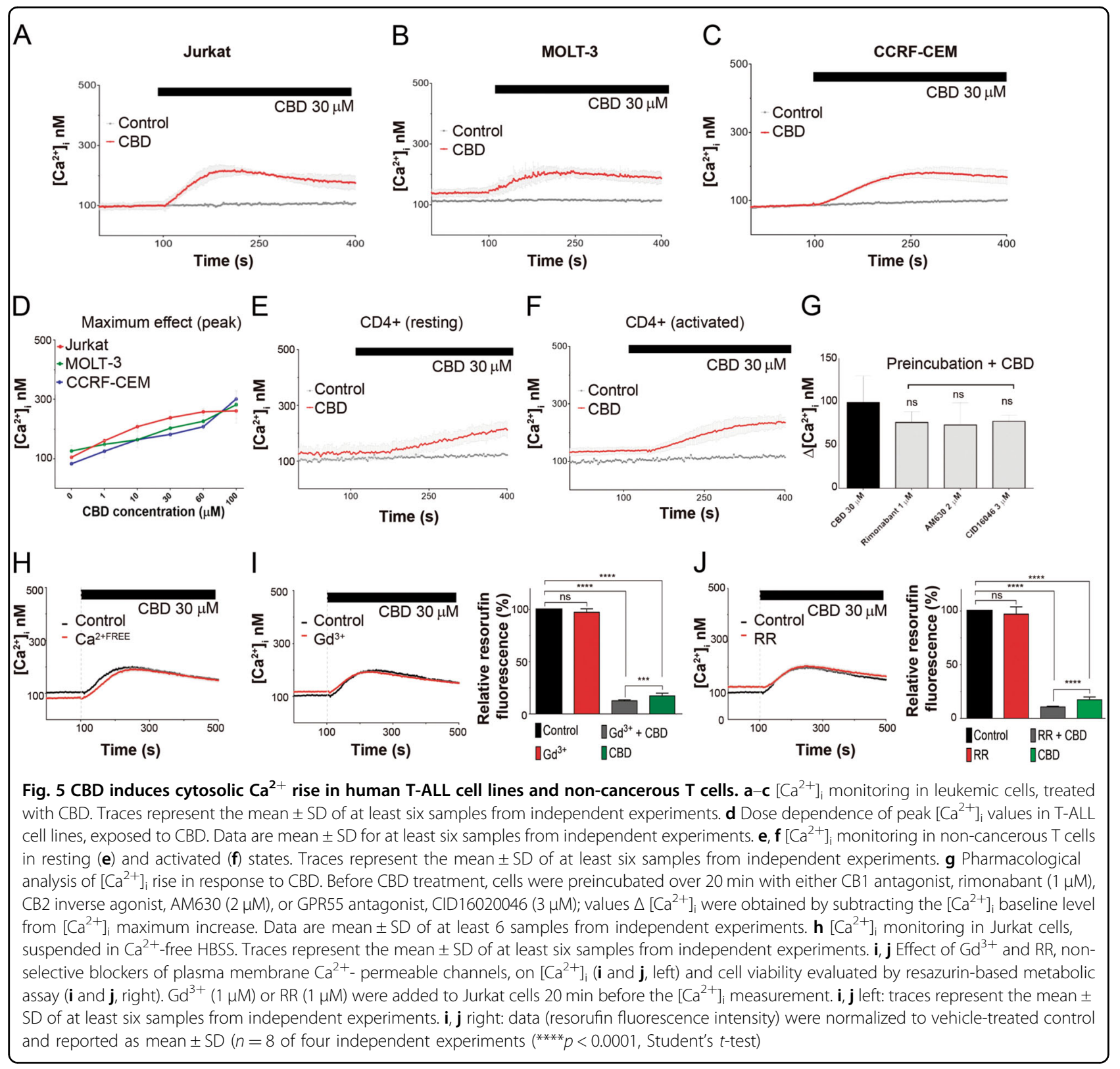

$\left[\mathrm{Ca}^{2+}\right]_{\mathrm{m}}$ signal was $\sim 5 \mu \mathrm{M}$, basing on the titration curve for CEPIA3mt ${ }^{28}$. Notably, CBD-induced $\left[\mathrm{Ca}^{2+}\right]_{\mathrm{m}}$ transient occurred at time when $\left[\mathrm{Ca}^{2+}\right]_{\mathrm{i}}$ remained at the resting level. Thus, causal relation between CBD-induced $\left[\mathrm{Ca}^{2+}\right]_{\mathrm{m}}$ and $\left[\mathrm{Ca}^{2+}\right]_{\mathrm{i}}$ increases was further addressed. Jurkat cells highly express functional $\mathrm{H} 1$ histamine receptors and histamine treatment was proved to induce the inositol 1,4,5-trisphosphate receptor $\left(\mathrm{IP}_{3} \mathrm{R}\right)$-dependent $\mathrm{Ca}^{2+}$ release from the ER for this cell model ${ }^{29}$. Artificial depletion of the $\mathrm{ER} \mathrm{Ca}^{2+}$ by histamine or thapsigargin and block of the $\mathrm{ER} \mathrm{Ca}^{2+}$ release via $\mathrm{IP}_{3} \mathrm{R}$ channels by 2 -aminoethoxydiphenyl borate (2$\mathrm{APB})$ abolished the $\mathrm{CBD}$-induced $\left[\mathrm{Ca}^{2+}\right]_{\mathrm{i}}$ increase. Thus, ER was the source of the CBD-induced $\left[\mathrm{Ca}^{2+}\right]_{\mathrm{i}}$ rise (Fig. 6c, d, f). CBD-induced $\left[\mathrm{Ca}^{2+}\right]_{\mathrm{m}}$ rise was potentiated by ER $\mathrm{Ca}^{2+}$ release (and concomitant cytosolic $\mathrm{Ca}^{2+}$ rise) and reduced upon the conditions, when $\mathrm{ER} \mathrm{Ca}^{2+}$ release was blocked (Fig. $6 \mathrm{c}-\mathrm{e}$ ). Thus, $\mathrm{ER} \mathrm{Ca}^{2+}$ release partly fuels the CBD-induced $\left[\mathrm{Ca}^{2+}\right]_{\mathrm{m}}$ rise. However, note that $\left[\mathrm{Ca}^{2+}\right]_{\mathrm{m}}$ rise was switched first upon CBD administration, not by $\mathrm{Ca}^{2+}$ release from the ER per se. Mitochondria act as a sink for $\mathrm{Ca}^{2+}$, artificially released from the ER prior to CBD application as evidenced by an abrupt decrease of $\left[\mathrm{Ca}^{2+}\right]_{\mathrm{i}}$ in a response to CBD (Fig. 6c, f).

$\mathrm{Ca}^{2+}$ uptake from the cytosol to mitochondria is mediated by voltage-dependent anion channel (VDAC) in the $\mathrm{OMM}$ and the mitochondrial $\mathrm{Ca}^{2+}$ uniporter (MCU) 


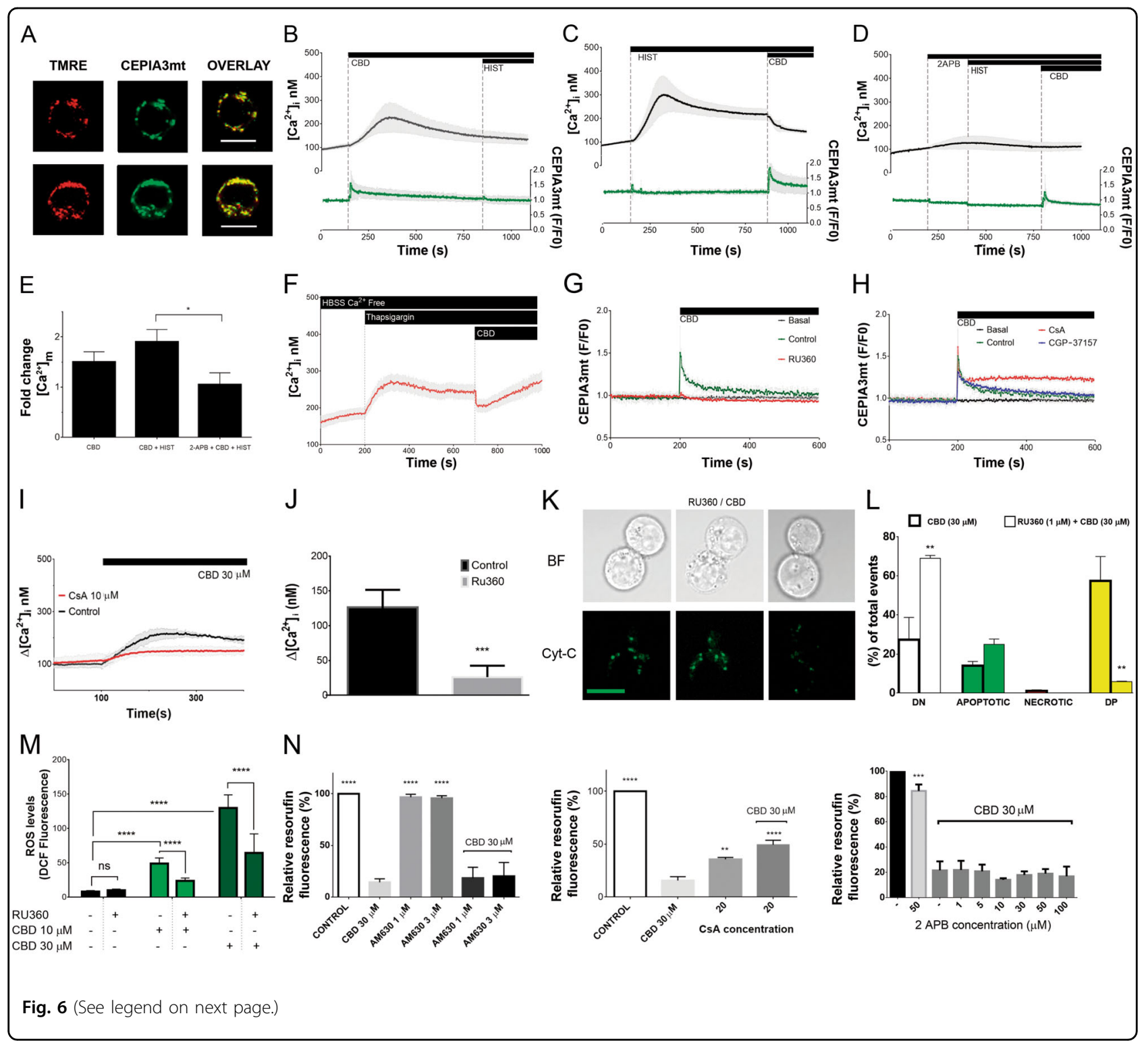

in the inner mitochondrial membrane (IMM). In our experiments, CBD-induced $\left[\mathrm{Ca}^{2+}\right]_{\mathrm{m}}$ rise was completely suppressed by a permeable MCU blocker Ru360 (Fig. 6g), but not significantly affected by CGP-37157, the inhibitor of the inner membrane $\mathrm{Na}^{+} / \mathrm{Ca}^{2+}$ exchanger, NCX (Fig. 6h). Specific inhibitor of $\mathrm{mPTP}, \mathrm{CsA}$, stabilized $\left[\mathrm{Ca}^{2+}\right]_{\mathrm{m}}$ at a high level (Fig. 6h). Of special note, the inhibition of mitochondrial $\mathrm{Ca}^{2+}$ overload and of mPTP by Ru360 and CsA, respectively, precluded the cytosolic $\mathrm{Ca}^{2+}$ rise (Fig. $6 \mathrm{i}-\mathrm{j}$ ). Thus, the ER $\mathrm{Ca}^{2+}$ release is causally dependent on the mitochondrial response. Collectively, our $\left[\mathrm{Ca}^{2+}\right]_{\mathrm{m}}$ data imply that CBD-induced $\mathrm{Ca}^{2+}$ uptake into the mitochondrial matrix via MCU caused a rapid $\left[\mathrm{Ca}^{2+}\right]_{\mathrm{m}}$ overload, which induced the mPTP opening and a subsequent $\left[\mathrm{Ca}^{2+}\right]_{\mathrm{m}}$ release. Thus, mitochondria appear to be a primary target for $\mathrm{CBD}$ and $\mathrm{mPTP}$ opening is required for the induction of $\mathrm{Ca}^{2+}$ release from the ER. MCU inhibitor Ru360 prevented CBD-induced ROS formation, Cyt-C release and cell death as revealed by Annexin V/PI assay (Fig. 6k-m). The last result is very essential, because it links mitochondrial $\mathrm{Ca}^{2+}$ overload to cell death. Remarkably, CsA, albeit per se possessing immunosuppressing activity, partially improved cell viability of CBD-treated cells, while CB2 inverse agonist AM630 and 2-APB were inefficient (Fig. 6n).

\section{CBD interacts directly with mitochondria to promote the organelle dysfunction}

To verify the conclusion that mitochondria are direct targets for $\mathrm{CBD}$ action, mitochondria were freshly isolated 
(see figure on previous page)

Fig. 6 CBD directly induces mitochondrial $\mathrm{Ca}^{2+}$ overload and mPTP opening. a CEPIA3mt fluorescence is colocalized with mitochondrial marker TMRE in Jurkat cells. Scale bar: $10 \mu \mathrm{m}$. b-d Concurrent monitoring of $\left[\mathrm{Ca}^{2+}\right]_{\mathrm{i}}$ and $\left[\mathrm{Ca}^{2+}\right]_{\mathrm{m}}$ in Jurkat cells. $\left[\mathrm{Ca}^{2+}\right]_{i}$ and $\left[\mathrm{Ca}^{2+}\right]_{\mathrm{m}}$ changes were evaluated with Fura-2 $(2 \mu \mathrm{M})$ and CEPIA3mt, respectively. Note that cells were loaded either with Fura-2 or with CEPIA3mt; individual time courses for Fura-2 and CEPIA3mt, were synchronized with respect to the timepoint of CBD addition and averaged $\left[\mathrm{Ca}^{2+}\right]_{i}$ and $\left[\mathrm{Ca}^{2+}\right]_{\mathrm{m}}$ responses were plotted at the upper and lower panels, respectively. CBD $(30 \mu \mathrm{M})$, histamine $(10 \mu \mathrm{M})$ and membrane-permeable $\mathrm{P}_{3} \mathrm{R}$ blocker 2 APB $(50 \mu \mathrm{M} \mu \mathrm{M})$ were added as indicated. Traces are mean \pm SD of at least six samples from independent experiments. e Peak values for $\left[\mathrm{Ca}^{2+}\right]_{\mathrm{m}}$ changes, induced by $\mathrm{CBD}$, from the experiments shown in $\mathbf{b}-\mathbf{d}$, with a variable level of $\left[\mathrm{Ca}^{2+}\right]_{i}$ due to manipulations with $\mathrm{Ca}^{2+}$ release from the ER. Bars represent mean $\pm S D$ of at least six samples from independent experiments. One-way ANOVA test $\left({ }^{*} p<0.05\right) . \mathbf{f}\left[\mathrm{Ca}^{2+}\right]_{\mathrm{i}}$ monitoring in Jurkat cells, loaded with Fura-2 $(2 \mu \mathrm{M})$. ER Ca ${ }^{2+}$ was depleted by thapsigargin $(1 \mu \mathrm{M})$. Experiments were performed in $\mathrm{Ca}^{2+}$-free medium (HBSS). Addition of CBD causes an abrupt decrease of $\left[\mathrm{Ca}{ }^{2+}\right]_{\mathrm{i}}$ ( $c f$ with $\mathbf{c}$ ). Traces are mean \pm SD of at least three samples from independent experiments. $\mathbf{g}, \mathbf{h}\left[\mathrm{Ca}^{2+}\right]_{m}$ monitoring in Jurkat cells, transfected with

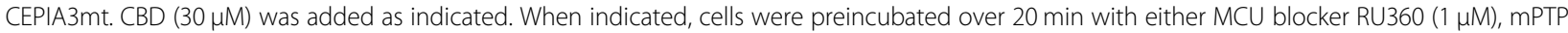
inhibitor CSA $(10 \mu \mathrm{M})$, or inhibitor of mitochondrial $\mathrm{Na}^{+} / \mathrm{Ca}^{2+}$ exchanger NCLX CGP37157 $(1 \mu \mathrm{M})$. Traces are mean \pm SD of at least six samples from independent experiments. $\mathbf{i}\left[\mathrm{Ca}^{2+}\right]_{\mathrm{i}}$ monitoring in Jurkat cells, loaded with Fura-2 $(2 \mu \mathrm{M})$. CBD $(30 \mu \mathrm{M})$ was added as indicated. Cells were preincubated during $20 \mathrm{~min}$ with vehicle or $\operatorname{CsA}(10 \mu \mathrm{M})$, specific inhibitor of the mPTP. Values $\Delta\left[\mathrm{Ca}^{2+}\right]_{i}$ were obtained by subtracting the $\left[\mathrm{Ca}^{2+}\right]_{\text {; }}$ baseline level from the peak $\left[\mathrm{Ca}^{2+}\right]_{\text {. }}$. Traces are $\pm \mathrm{SD}$ of at least six samples from independent experiments. $\mathbf{j}$ Cytosolic Ca ${ }^{2+}$ response to CBD (30 $\left.\mu \mathrm{M}\right)$ in Jurkat cells was abolished by a preincubation with the MCU blocker Ru360 $(1 \mu \mathrm{M})$ over $20 \mathrm{~min}$. Values $\Delta\left[\mathrm{Ca}^{2+}\right]_{i}$ were obtained by subtracting the $\left[\mathrm{Ca}^{2+}\right]_{\mathrm{i}}$ baseline level from peak $\left[\mathrm{Ca}^{2+}\right]_{\mathrm{i}}$. Data are mean \pm SD of a minimum of six independent experiments $\left({ }^{* *} p<0.01\right.$; ${ }^{* * *} p<0.001$; Student's $t$-test). k Representative images of Jurkat cells, transfected with EYFP-Cyt-C, pretreated with RU360 (1 $\mu \mathrm{M}, 20$ min), and subsequently treated with CBD (30 $\mu \mathrm{M}, 1 \mathrm{~h}$ ). Discrete green fluorescent puncta (pseudocolor) represent Cyt-C localization in intact mitochondria whereas Cyt-C release from mitochondria is evidenced by a more diffuse EYFP-Cyt-C distribution. Compare these images with Fig. 4d, e (vehicle- and CBD-treated cells) and note the protective effect of RU360. Scale bar: $10 \mu \mathrm{m}$. I MCU blocker RU360 effectively prevents CBD-induced cell death in Jurkat cells. Cell death was evaluated by flow cytometry, using Annexin V-AF488/PI double staining. Cells were preincubated with vehicle or RU360 (1 $\mu \mathrm{M}, 2 \mathrm{~min})$, and then treated with $\mathrm{CBD}(30 \mu \mathrm{M}, 6 \mathrm{~h})$. Data of three independent experiments are present $\left({ }^{* *} p<0.01\right.$, one-way ANOVA test). $\mathbf{m}$ ROS levels were evaluated by DCF fluorescence intensity. Cells were either only treated with CBD (10 or $30 \mu \mathrm{M}, 1 \mathrm{~h}$, light and dark green bars, respectively) or additionally pretreated with RU360 (1 MM, 20 min). In all, 50 cells from at least three independent experiments were analyzed for each condition. Data are mean of \pm SD. Statistic comparisons between control and CBD-treated samples, or between RU360-pretreated and non-pretreated samples were performed. ${ }^{* * * *} p<0.0001$, one-way ANOVA. $\mathbf{n}$ Effects of the CB2 inverse agonist, AM630 $(n=8), \mathrm{mPTP}$ inhibitor CSA $(n=6)$ and membrane-permeable $\mathrm{PP}_{3} \mathrm{R}$ blocker 2APB $(n=6)$ on the viability of Jurkat cells, treated with CBD. Cell viability was evaluated by resazurin-based metabolic assay ( $24 \mathrm{~h}$ ). Data are mean \pm SD. Statistical comparison was made in relation to CBD-treated samples; ${ }^{*} p<0.05 ;{ }^{* *} p<0.01 ;{ }^{* * *} p<0.001$; ${ }^{* * *} p<0.0001$, one-way ANOVA

from Jurkat cells. Mitochondria were stained with MtGreen and fluorescent $\mathrm{Ca}^{2+}$ indicator Rhod-2, and evaluated by flow cytometry. High percentage of doublestained particles evidenced high purity of mitochondria population (Fig. 7a). Upon exposure to $30 \mu \mathrm{M}$ CBD isolated mitochondria exhibited $\left[\mathrm{Ca}^{2+}\right]_{\mathrm{m}}$ increase at external free $\mathrm{Ca}^{2+}$ of $100 \mathrm{nM}$, equal to the resting cytosolic $\mathrm{Ca}^{2+}$ level (Fig. 7b). The response of high affinity $\mathrm{Ca}^{2+}$ indicator Rhod-2 (Kd $\sim 0.6 \mu \mathrm{M})$ was saturated, implying that free $\left[\mathrm{Ca}^{2+}\right]_{\mathrm{m}}$ level was above $1 \mu \mathrm{M}$ for a long time. Incubation of isolated mitochondria with CBD over $10 \mathrm{~min}$ produced a strong dose-dependent decrease of $\Delta \Psi \mathrm{m}$ (Fig. 7c), similar to that in whole cells (Fig. 4b).

\section{CBD binding to VDAC: in silico evidences}

In some cell models $\mathrm{CBD}$ can induce cell death via direct interaction with VDAC, promoting its closure to a conformational substate ${ }^{30}$. This substate possesses a reduced capacity to transport metabolites and increased $\mathrm{Ca}^{2+}$ permeability ${ }^{31}$. We performed in silico analysis of VDAC- CBD interactions. VDAC surface and N-terminus were tested for CBD binding. Among the main VDAC cavities, $\beta 9-12$ and $\mathrm{N}$-terminus regions exhibited the most suitable sites for the $\mathrm{CBD}$ binding, basing on respective free energy changes (docking score, see Supplementary Table 1). 3D analysis of the CBD-VDAC interaction revealed that more likely CBD interacts with 3 residues, Thr9, Asp12, and Leu13 at the N-terminus and neighboring pore residues Val146, Gln157, Gly175, Gln182, and His184 (Fig. 7d). Further analysis revealed that CBD binding is stabilized mainly by steric interactions and hydrogen bonds (Fig. 7e). Of putative CBDinteracting residues, Thr9, Asp 12, and Hist184 have a highest contribution to the overall binding energy (Supplementary Fig. 1, Supplementary Table 1).

\section{Discussion}

A crucial role of mitochondria in cell metabolism and bioenergetics, as well as in signaling pathways, regulation of transcriptional activity, proliferation, migration, and cell death is tightly related to their involvement into the intracellular $\mathrm{Ca}^{2+}$ dynamics ${ }^{32}$. In the present study, by means of concurrent monitoring of $\left[\mathrm{Ca}^{2+}\right]_{\mathrm{m}}$ and $\left[\mathrm{Ca}^{2+}\right]_{\mathrm{i}}$ in a response to the $\mathrm{CBD}$ treatment, we have provided the experimental evidences that mitochondria are primary CBD target in T-ALL. In the first place, acute transient $\left[\mathrm{Ca}^{2+}\right]_{\mathrm{m}}$ rise, preceding the $\left[\mathrm{Ca}^{2+}\right]_{\mathrm{i}}$ increase, was observed in a response to CBD (Fig. 6b). Furthermore, $\left[\mathrm{Ca}^{2+}\right]_{\mathrm{m}}$ increase together with a dissipation of $\triangle \Psi \mathrm{m}$ was observed also in isolated mitochondria, treated with CBD (Fig. 7b, c). $\mathrm{Ca}^{2+}$ accumulation in mitochondrial matrix requires the crossing of both OMM and IMM. VDAC channel, 

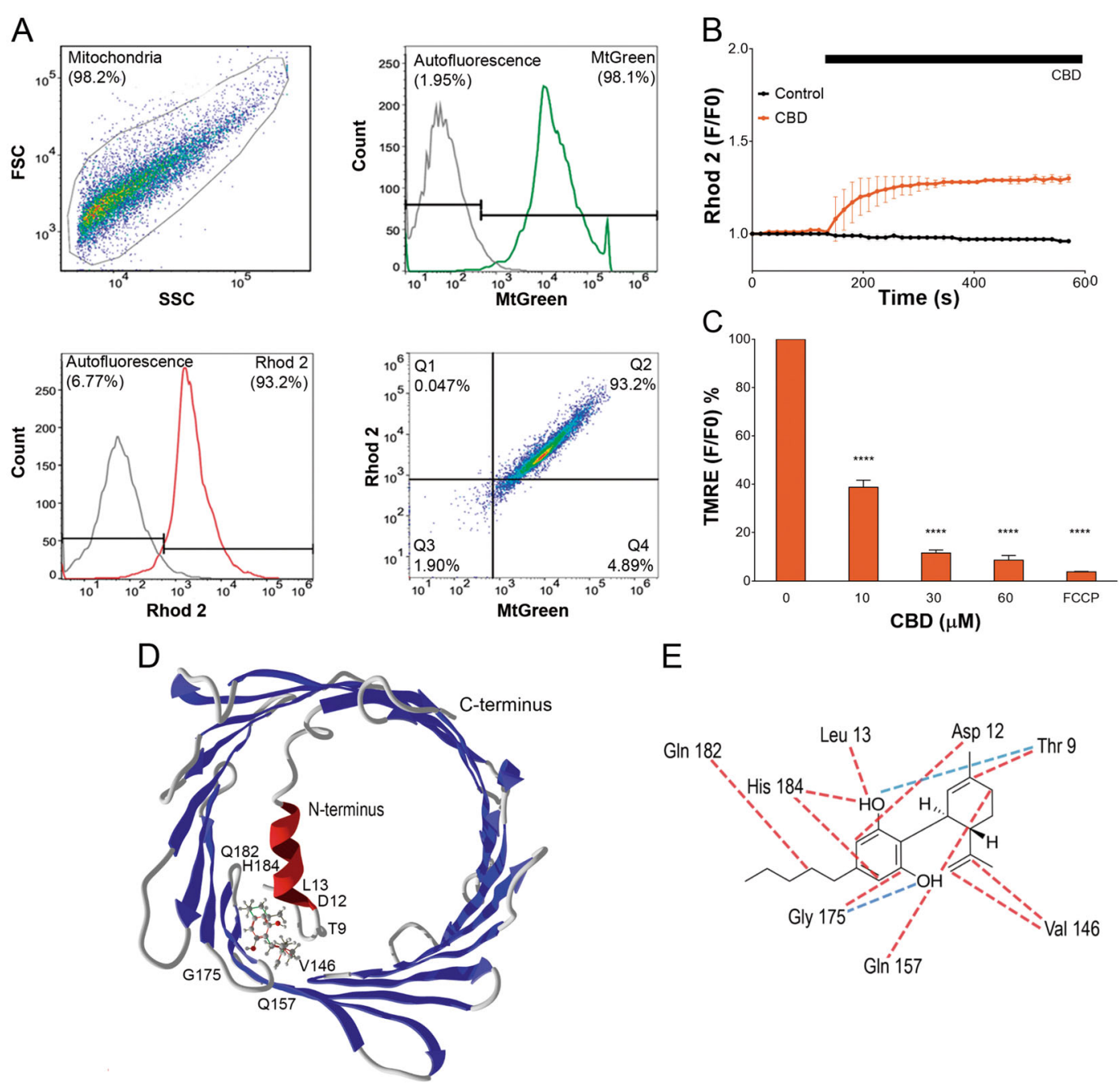

$E$

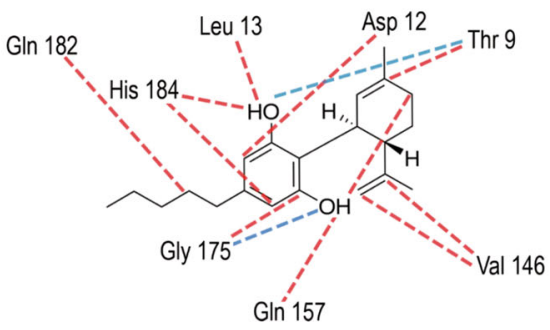

Fig. 7 CBD directly interacts with mitochondria. a Isolation of mitochondria from Jurkat cells was corroborated by flow cytometry analysis. Representative experiment is shown. The purity of mitochondria population was determined as a percentage of double positive particles after

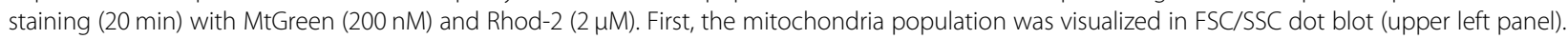
Non-stained mitochondria were used to determine the autofluorescence interval (gray histograms and corresponding intervals in upper right and lower left panels). Accordingly, positive intervals for MtGreen (green histogram and corresponding interval in upper right panel) and Rhod-2 (red histogram and corresponding interval in lower left panel) were determined. More than $90 \%$ of freshly isolated mitochondria were double-positive (lower right panel). Freshly isolated mitochondria were assayed immediately. $\mathbf{b}\left[\mathrm{Ca}^{2+}\right]_{\mathrm{m}}$ uptake by freshly isolated mitochondria in a response to vehicle or CBD $(30 \mu \mathrm{M})$ treatments. Traces are mean \pm SD for three independent experiments. c CBD effect on membrane potential $(\triangle \psi \mathrm{m})$ in isolated mitochondria. Freshly isolated mitochondria were stained with TMRE (400 nM) and exposed to different CBD concentrations for 10 min. FCCP was used as a positive control. Data are mean \pm SD of at least three independent experiments (**** $p<0.0001$, one-way ANOVA test). $\mathbf{d}$ In silico analysis predicts that CBD interacts with VDAC1 at N-terminus and $\beta 9-11$ residues. e Residues, interacting with CBD are depicted; hydrogen bonding interactions are colored in red, whereas steric interactions are depicted in blue

ubiquitously expressed in OMM, is normally responsible for the OMM permeability to $\mathrm{Ca}^{2+33}$. Under physiological conditions, VDAC permeability to $\mathrm{Ca}^{2+}$ at levels, required for an optimal function of TCA enzymes, is regulated by VDAC interaction with $\mathrm{IP}_{3} \mathrm{R}$ in ER and chaperone $75 \mathrm{kDa}$ glucose-regulated protein GRP7 $5^{34}$. Our in silico analysis which demonstrated that CBD may interact directly with VDAC (Fig. 7) is in agreement with findings by others that CBD colocalizes with VDAC-rich mitochondrial membranes fraction from BV-2 microglia cell line and that purified VDAC, incorporated into lipid bilayers, is switched from fully open to major subconductance state by $\mathrm{CBD}^{30}$. Such "closed" channel state is known to be highly permeable for $\mathrm{Ca}^{2+}$, due to the exposure of anionic groups within the channel pore ${ }^{31}$.

Based on the available data, the following working model can be proposed (Fig. 8). Due to its direct interaction with CBD, VDAC1 is "fixed" in the $\mathrm{Ca}^{2+}$-permeable state. This 


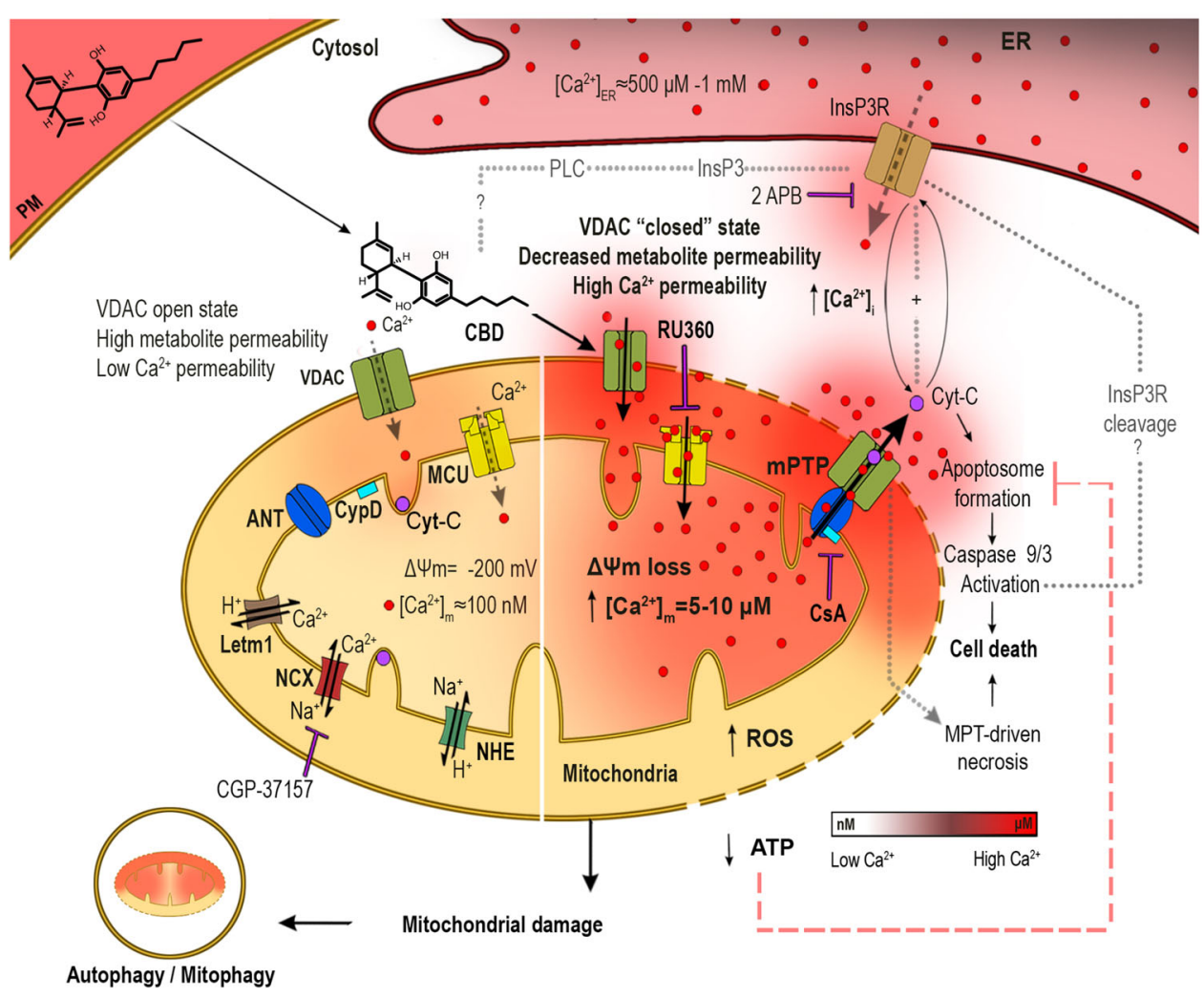

Fig. 8 Proposed mechanism for the CBD effect on T-ALL cells. Highly lipophilic CBD readily permeates plasma membrane and enters the cytosol, approaching mitochondria. Direct CBD interaction with VDAC favors the channel closed substate with increased $\mathrm{Ca}^{2+}$ permeability. It favors mitochondrial $\mathrm{Ca}^{2+}$ uptake through VDAC and MCU, leading to the mitochondrial $\mathrm{Ca}^{2+}$ overload that promotes the mPTP formation, $\triangle \psi m$ loss, mitochondrial swelling, and cristae disruption. mPTP opening promotes the Cyt-C release from mitochondria. In cytoplasm, Cyt-C may orchestrate the apoptosome formation, caspases' activation, and triggers the intrinsic apoptosis. MPTP rapidly triggers $\mathrm{Ca}^{2+}$ release from the ER, which tends to promote the mitochondrial $\mathrm{Ca}^{2+}$ overload in a feedforward manner. The CBD-induced dysfunction of mitochondria is accompanied by severe oxidative stress and rapid loss of ATP production, resulting in the MPT-driven necrosis. Autophagy occurs in T-ALL cells treated with sublethal CBD concentrations

causes $\mathrm{Ca}^{2+}$ entry into the intermembrane space. $\mathrm{Ca}^{2+}$ needs to concentrate to micromolar level there, to unlock and activate the $\mathrm{MCU}^{35}$. This is commonly believed to be induced by a substantial increase of extramitochondrial $\mathrm{Ca}^{2+}$. Our data suggest that mitochondrial $\mathrm{Ca}^{2+}$ overload occurred already at resting $0.1 \mu \mathrm{M}$ cytosolic $\mathrm{Ca}^{2+}$ (Figs. 6b, $\mathrm{d}$ and $7 \mathrm{~b}$ ). The driving force for $\mathrm{Ca}^{2+}$ accumulation within the intermembrane space could be a negative Donnan potential of -20 to $-40 \mathrm{mV}$ across the $\mathrm{OMM}^{36}$. This allows the concentration of $\mathrm{Ca}^{2+}$ in the intermembrane space up to 20-fold as compared to the cytosolic $\mathrm{Ca}^{2+}$ concentration, providing that the outer membrane is permeable for $\mathrm{Ca}^{2+}$. The magnitude of the Donnan potential across the OMM depends on the accumulation of impermeable large anions within the intermembrane space. Such accumulation, e.g. of ATP, may be provoked by the same conformational shift within VDAC1, which not only increases its $\mathrm{Ca}^{2+}$ permeability, but also makes it adenine nucleotide-impermeable ${ }^{36}$. Activation of $\mathrm{MCU}$ along with a large negative potential across the IMM drives $\mathrm{Ca}^{2+}$ entry into the mitochondrial matrix, leading to a rapid $\left[\mathrm{Ca}^{2+}\right]_{\mathrm{m}}$ overload (Fig. 6). The latter triggers a stable MPTP formation, which causes depolarization of the IMM, mitochondrial dysfunction, severe oxidative stress, and $\mathrm{Ca}^{2+}$ and $\mathrm{Cyt}-\mathrm{C}$ release into the cytosol.

Noteworthy, multiple leukemic phenotypes express higher levels of VDAC in a comparison to healthy cells and VDAC expression is increased upon chemotherapy. Moreover, the degree of overexpression is positively correlated with the cell death induction by anticancer agents $^{37-39}$.

We have observed different outcome of the CBD treatment depending on its concentration. At high CBD concentration, various scenarios of regulated cell death may be triggered in LLA-T (Fig. 8). In the present study, we reported apoptotic features such as Cyt-C release from mitochondria to cytosol, activation of caspases $9 / 3$ and externalization of phosphatidylserine. On the other hand, appearance of the huge Annexin $\mathrm{V}^{+} \mathrm{PI}^{+}$population in the early phases of CBD treatment evidenced MPT-driven 
necrosis. One can hypothesize that development of MPTdriven apoptosis may be blocked due to energy penalty, a decreased ATP level caused by a cessation of oxidative phosphorylation by defunct mitochondria ${ }^{40}$. At sublethal (10 $\mu \mathrm{M}$ CBD) concentration, autophagy was induced and apparently efficiently prevented cell death (Fig. 1b, c, g, h; Fig. 3a-d). Low CBD concentrations even stimulated cell proliferation (Fig. 1b). This phenomenon may be explained in the frame of the same basic model, providing they promoted only limited $\left[\mathrm{Ca}^{2+}\right]_{\mathrm{m}}$ increase. Such moderate $\left[\mathrm{Ca}^{2+}\right]_{\mathrm{m}}$ accelerates metabolism due to $\mathrm{Ca}^{2+}$-dependence of TCA cycle enzymes ${ }^{41}$.

In conclusion, CBD directly targets mitochondria in $\mathrm{T}$ ALL and changes their capacity to handle $\mathrm{Ca}^{2+}$, which in turn affects multiple cellular functions, including ROS production and $\mathrm{Ca}^{2+}$ signaling, metabolic switch and the induction of autophagy and cell death. The latter is directly proved for our experimental model as the inhibitor of mitochondrial $\mathrm{Ca}^{2+}$ uptake Ru360 protected TALL cells from the CBD-induced cell death. Considering the pivotal role of mitochondria in oncogenic re-programming, CBD may be plausible candidate to be included into chemotherapeutic protocols. Importantly, resting $\mathrm{T}$ cells, representing major $\mathrm{T}$ lymphocyte population, were resistant to $\mathrm{CBD}$ and retained their ability to antigen activation. Healthy activated T cells were CBD-sensitive, but this population is small in T-ALL patients with a weakened immunologic system. However, contrasting effects of low and high CBD concentrations and possible differences in its tissue distribution and bioavailability requires further studies on animal models, with a focus on safety issues.

\section{Materials/subjects and methods \\ Cell lines and culture conditions}

Leukemic cell lines Jurkat (ATCC ${ }^{\oplus} \mathrm{TIB}^{\mathrm{TM}}$, Clone E6-1, male, 14 years), MOLT-3 (ATCC ${ }^{\circledR}$ CRL-1552 ${ }^{\mathrm{TM}}$, male, 19 years), CCFR-CEM (ATCC ${ }^{\circledR}$ CCL-119 ${ }^{\mathrm{TM}}$, T-ALL, female, 4 years), K562 (ATCC ${ }^{\circledR} \mathrm{CCL}-243^{\mathrm{TM}}$, female, 53 years), Reh $\left(\mathrm{ATCC}^{\circledR} \mathrm{CRL}-8286^{\mathrm{TM}}\right.$, female) and RS4;11 (ATCC ${ }^{\circledR} \mathrm{CRL}-$ $1873^{\mathrm{TM}}$, female, 32 years) purchased from ATCC ${ }^{\circledR}$ (Manassas, VA, USA) were grown in suspension in Advanced RPMI 1640 medium, supplemented with $5 \%(\mathrm{v} / \mathrm{v})$ of heatinactivated fetal bovine serum (FBS), $100 \mathrm{U} / \mathrm{mL}$ of penicillin, $100 \mu \mathrm{g} / \mathrm{mL}$ streptomycin and $1 \%$ of GlutaMAX ${ }^{\mathrm{Tm}}$ (all from Invitrogene, Carlsbad, CA, USA). Tandem-labeled mCherry-GFP-LC3 Jurkat cells (gift from Dr. A. Thorburn, Colorado, USA) were maintained in complete growth medium (as for wild type Jurkat cells), additionally supplemented with $400 \mu \mathrm{g} / \mathrm{mL}$ of hygromycin B (Sigma, H3274) for selection. Suspension cells were maintained in the logarithmic growth phase by daily medium refreshment. Adherent cell lines MDA-MB-231 (ATCC ${ }^{\circledR} \mathrm{HTB}-$ $26^{\mathrm{TM}}$, female, 51 years), MCF7 (ATCC ${ }^{\circledR} \mathrm{HTB}-22^{\mathrm{TM}}$, female,
69 years), $\mathrm{SiHa}$ (ATCC ${ }^{\circledR} \mathrm{HTB}-35^{\mathrm{TM}}$, female, 55 years) and HeLa (ATCC ${ }^{\circledR}$ CCL- $2^{\mathrm{TM}}$, female, 31 years) were maintained in DMEM medium supplemented with $10 \%(\mathrm{v} / \mathrm{v})$ of heatinactivated FBS, $100 \mathrm{U} / \mathrm{mL}$ of penicillin, $100 \mu \mathrm{g} / \mathrm{mL}$ streptomycin and $1 \%$ of GlutaMAX ${ }^{\mathrm{TM}}$. Adherent cells were passaged when they were in the logarithmic growth phase. All cells were cultured in a humidified incubator in 5\% $\mathrm{CO}_{2} / 95 \%$ air atmosphere at $37^{\circ} \mathrm{C}$.

\section{Human samples}

Blood samples $(10 \mathrm{~mL})$ from non-cancerous, apparently healthy volunteers (6 males and 6 females, younger than 35 years) were collected by capacitated personal under aseptic conditions. A written informed consent was obtained from all persons, prior to sample collection, according to the Declaration of Helsinki. Sample acquisition protocol was evaluated and approved by the Bioethics and Biosecurity Committee of the Biomedical Research Centre and the Faculty of Medicine of the University of Colima, in agreement with the federal laws (Artículo 100, Ley General de Salud).

\section{Cannabidiol}

CBD solution in methanol $(10 \mathrm{mg} / \mathrm{mL}$, equivalent to $32 \mathrm{mM}$ ) was purchased from Cayman Chemical (90081) and stored at $-20{ }^{\circ} \mathrm{C}$. Working solutions in complete growth medium were prepared daily. Methanol (154903, Merck) was used in vehicle-treated controls. Reference methanol concentration for a vehicle control was $0.3 \% \mathrm{v} / \mathrm{v}$, which corresponds to that applied with the highest tested CBD concentration $(100 \mu \mathrm{M})$.

\section{Purification and activation of $\mathrm{CD}^{+}$lymphocytes}

Heparinized freshly isolated blood samples were diluted 1:1 with cold PBS. Peripheral blood mononuclear cells (PBMC) were separated by centrifugation in Ficoll (17144002, Ficoll-Paque 1.073, GE Healthcare) gradient (1:1.5 blood/Ficoll ratio, $1000 \times g, 30 \mathrm{~min}, \mathrm{RT})$. PBMC were collected from the interphase and carefully washed in PBS. Finally, cells were resuspended in a fresh RPMI 1640 medium, supplemented with $10 \%$ of FBS and incubated overnight for cell recovery. Next day, PBMC were subjected to negative selection (to avoid activation) with human $\mathrm{CD}^{+} \mathrm{T}$ cell isolation kit (130-096-533, Miltenyi Biotec Miltenyi Biotec), following manufacturers' specifications. Briefly, PBMC were collected, washed $(400 \times g$, $5 \mathrm{~min}$ ) and the pellet was resuspended in cold MACS buffer. Live cells were counted (trypan blue exclusion test) and incubated with $\mathrm{CD} 4^{+} \mathrm{T}$ cell biotin-antibody cocktail $\left(1 \mu \mathrm{L} / 1 \times 10^{6}\right.$ cells $)$ against CD8a, CD11b, CD11c, CD19, CD45R (B220), CD49b (DX5), CD105, Anti-MHC Class II, Ter- 119 , and $\mathrm{TCR} \gamma / \delta$, for $20 \mathrm{~min}$ at $4{ }^{\circ} \mathrm{C}$ with agitation, followed by incubation with microbeads, conjugated to monoclonal anti- biotin antibodies $\left(2 \mu \mathrm{L} / 1 \times 10^{6}\right.$ cells $)$ 
over $20 \mathrm{~min}$ at $4{ }^{\circ} \mathrm{C}$. Next, $1 \mathrm{~mL}$ of MACS buffer was added, cells were centrifuged $(400 \times g, 5 \mathrm{~min})$, supernatant was discarded to remove the excess of antibodies and cells were resuspended in $1 \mathrm{~mL}$ of cold MACS buffer. CD $4^{+} \mathrm{T}$ cell population was separated using a MACS separator. LS column was placed in the MAC separator, rinsed with $3 \mathrm{~mL}$ of MACS buffer and cell suspension was added. Enriched $\mathrm{CD}^{+} \mathrm{T}$ (negative) cells were collected and column was washed three times with MACS buffer for a complete $\mathrm{CD} 4^{+}$harvesting. Enriched $\mathrm{CD} 4^{+} \mathrm{T}$ cell population was centrifuged $(400 \times g, 5 \mathrm{~min})$, resuspended in complete Advanced RPMI 1640 medium and incubated at $37^{\circ} \mathrm{C}$ in a humidified atmosphere $\left(5 \% \mathrm{CO}_{2}, 95 \%\right.$ air $)$ prior to the experiments. The population purity was more than 95\% as verified by flow cytometry (FACSCanto II, BD Biosciences), using antiCD4 antibodies (BioLegend 357404).

For polyclonal activation, resting $\mathrm{CD}^{+}$lymphocytes were pretreated in 96-well plates with antiCD3 monoclonal antibodies $(5 \mu \mathrm{g} / \mathrm{mL})(\mathrm{BD}, 555336)$ for $2 \mathrm{~h}$ at $37^{\circ} \mathrm{C}$. Medium excess was removed and cells were further incubated with antiCD28 monoclonal antibodies $(2 \mu \mathrm{g} / \mathrm{mL})$ (BD, 555725) for 4 days. Ligation of CD3/CD28 provides an antigen-independent activation stimulus by cross-linking $\mathrm{T}$ cell receptor (TCR), resulting in transit from quiescent to proliferation state.

\section{Resazurin-based metabolic assay}

To estimate cell drug toxicity, resazurin-based metabolic assay was used. Bioreduction of resazurin reagent (Tox 8, Sigma-Aldrich) by viable cells reduces the amount of its oxidized form and concomitantly increases the amount of its fluorescent intermediate resorufin. The amount of dye conversion in solution was measured fluorometrically, using a fluorescence plate reader GloMax Discover (PROMEGA). Cells $\left(10^{6} / \mathrm{mL}\right)$ were seeded into 96-well plates in $180 \mu \mathrm{L}$ of complete RPMI medium per well. Cells were incubated $24 \mathrm{~h}$ without or with CBD $(1-100 \mu \mathrm{M})$. For assay, $20 \mu \mathrm{L}$ aliquots of resazurin reagent were added to each well to a final volume of $200 \mu \mathrm{L}$ and cells were further incubated for $4 \mathrm{~h}\left(37^{\circ} \mathrm{C}\right)$. Samples' fluorescence was measured by excitation at $520 \mathrm{~nm}$ and emission was collected at 580-640 nm. RPMI fluorescence was subtracted for each condition. Samples were run in triplicate, in at least three independent experiments. Data obtained from resorufin fluorescence were averaged, normalized to their controls and expressed as cell viability.

\section{Sequential CBD administration}

Jurkat cells $\left(2.5 \times 10^{5} / \mathrm{mL}\right.$ per well $)$ were seeded into a 48-well plate in complete Advanced RPMI medium. Cells were exposed to CBD $(1-100 \mu \mathrm{M}$, dissolved in $500 \mu \mathrm{L}$ of RPMI) and incubated for $24 \mathrm{~h}$. After incubation, cell culture was gently resuspended, and $10 \mu \mathrm{L}$ of suspension was taken for cell counting, using a hemocytometer and trypan blue exclusion test, to determine the number of viable cells. A second dose of CBD was administered, and cells were incubated for the next $24 \mathrm{~h}$. The procedure was repeated one more time, so that total assay was completed in $72 \mathrm{~h}$. Initial cell number was taken as $100 \%$, and daily cell count was normalized to this point. Three cell counts $(n=3)$ from three independent experiments were averaged and expressed as percentage of viability.

\section{$\mathrm{CD}^{+} \mathrm{T}$ cell recovery test}

Non-cancerous $\mathrm{CD} 4^{+} \mathrm{T}$-cells from healthy donors were cultured $\left(1 \times 10^{6}\right.$ cells $\left./ \mathrm{mL}\right)$ in complete Advanced RPMI 1640 medium. Cells were preincubated with CBD $(30 \mu \mathrm{M})$ or vehicle over $24 \mathrm{~h}$. After CBD treatment, cells were washed and resuspended in a CBD-free medium and used for activation with antiCD3 and antiCD28 antibodies, as described earlier. Cell viability was determined by resazurin-based metabolic assay (Tox8, Sigma-Aldrich) as previously described, using a fluorescence plate reader (GloMax Discover, PROMEGA). Samples were excited at $520 \mathrm{~nm}$ and emission was collected at 580-640 nm. RPMI fluorescence was subtracted for each condition and data was generated in triplicate, in at least three independent experiments. Data obtained from resorufin fluorescence were averaged, normalized to their control values and expressed as cell viability.

\section{Migration assay}

Leukemic cells were seeded in 12-well plates (3422, Transwell system, Corning Inc.) and preincubated for $1 \mathrm{~h}$ with CBD. Pretreated cells $\left(2 \times 10^{5}\right)$ were placed in $400 \mu \mathrm{L}$ of serum-free medium in the upper chamber of Transwell inserts ( $8 \mu \mathrm{M}$ pore size). Recombinant human CXCL12 (Sigma-Aldrich) was used as a chemoattractant $(100 \mathrm{ng} / \mathrm{mL})$ in the lower chamber, filled with complete RPMI (10\% FBS) medium. Cells were allowed to migrate over 4 hours. After incubation, insert was removed and cells from the lower chamber were counted, using hemocytometer. Migration was expressed as a percentage of migrated cells in relation to the total cell number.

\section{Cell death analysis}

For this assay, Alexa Fluor ${ }^{\circledR} 488$ Annexin V/Dead Cell Apoptosis Kit (V13241, Thermo Fisher Scientific) was used, following manufacturer specifications. Kit provides a nucleophilic marker (propidium iodide, PI, Ex/Em max $=535 / 617 \mathrm{~nm})$ as an indicator of plasma membrane damage and Annexin V-Alexa Fluor 488 (Ex/Em max = $488 / 510 \mathrm{~nm}$ ), binding to externalized phosphatidylserine (a hallmark of apoptosis). Jurkat cells $\left(10^{6} / \mathrm{mL}\right)$ were seeded in a 24 well plate and incubated with or without CBD $(0-100 \mu \mathrm{M})$ for determined period $(2,4,6$, or $12 \mathrm{~h})$. 
After the incubation period, cells were centrifuged $(400 \times$ $g)$ and washed with cold PBS. Then cells $\left(1 \times 10^{6}\right)$ were resuspended in $100 \mu \mathrm{L}$ of $1 \mathrm{X}$ Annexin V-binding buffer and $5 \mu \mathrm{L}$ of Annexin V conjugate with $1 \mu \mathrm{L}$ of PI working solution $(200 \mu \mathrm{g} / \mathrm{mL})$ were added. The mixture was incubated for $20 \mathrm{~min}$ at room temperature (protected from light), $200 \mu \mathrm{L}$ of Annexin V - binding buffer was added and cells were analyzed either by confocal microscopy (LSM 700, Carl Zeiss) or by flow cytometry (FACSCanto II, BD Biosciences).

For confocal microscopy, cells were placed into homemade coverslips-bottomed chambers (poly-L-lysinecoated coverslips were fixed at the bottom of chamber using Dow corning ${ }^{\oplus}$ high vacuum grease). $40 \times / 63 x$ oilimmersion objectives were used. For excitation, $488 \mathrm{~nm}$ laser was used for both Alexa Fluor 488 and PI. Raw data were further processed, and images were generated using Zen software (Zeiss).

For flow cytometry analysis, color compensation (Alexa Fluor 488 vs PI) was performed previously to data acquisition. $488 \mathrm{~nm}$ laser was used for excitation. PI fluorescence was measured using 556LP mirror and 585/ 42 filter, Alexa Fluor 488 fluorescence was measured using 502LP mirror and 530/30 filter. Debris and doublets were gated out, and 10,000 events of single cells per sample were collected. Autofluorescence control was used to determine the positive fluorescence threshold. Annexin $\mathrm{V}^{-} \mathrm{PI}^{-}$populations were classified as healthy, Annexin $\mathrm{V}^{+} \mathrm{PI}^{-}$as early apoptotic, Annexin $\mathrm{V}^{-} \mathrm{PI}^{+}$as primary necrotic, and Annexin $\mathrm{V}^{+} \mathrm{PI}^{+}$as necrotic/late apoptotic. Data analysis was performed with FlowJo 10.2 software.

\section{Determination of mitochondrial membrane potential}

Jurkat cells $\left(10^{6} / \mathrm{mL}\right)$ were double-labeled with MitoTracker $^{\mathrm{TM}}$ Green $(100 \mathrm{nM}, \mathrm{Ex} / \mathrm{Em} \max =490 / 518 \mathrm{~nm}$; M7514, Thermo Fisher Scientific) and TMRE (200 nM, $\mathrm{Ex} / \mathrm{Em} \max =555 / 582 \mathrm{~nm}$; T669, Thermo Fisher Scientific), both from Thermo Fisher Scientific, by incubating over $30 \mathrm{~min}$. After incubation period, cells were centrifuged $(400 \times g, 10 \mathrm{~min})$ and washed with Hanks Balanced Salt Solution (HBSS; $\mathrm{NaCl} 143 \mathrm{mM}, \mathrm{KCl} 6 \mathrm{mM}$, $\mathrm{MgSO}_{4} 5 \mathrm{mM}, \mathrm{CaCl}_{2} 1 \mathrm{mM}$, HEPES $20 \mathrm{mM}$, BSA $0.1 \%$, glucose $5 \mathrm{mM}, \mathrm{pH} 7.4, \approx 300 \mathrm{mOsm}$ ) to remove excessive dye. For imaging, cells were placed in home-made coverslips-bottomed chambers and analyzed by confocal microscopy (LSM 700, Carl Zeiss) in a time series mode. Images were acquired every second and raw data were further processed by ImageJ program, where regions of interest (ROI) were defined, based on MitoTracker Green distribution. The fluorescence of each ROI for both dyes (TMRE/MtGr) was then averaged and expressed as a temporal ratio between the fluorescence of each frame and the initial fluorescence (F/FO). To evaluate drugs' effect, CBD $(0-100 \mu \mathrm{M})$ or FCCP $(10 \mu \mathrm{M}$; C2920, Merck) were administered, and cells were incubated for $10 \mathrm{~min}$, centrifuged $(400 \times g, 10 \mathrm{~min})$, resuspended in HBSS, and transferred to a 96-well plate. TMRE retention was assessed by measurement of fluorescence intensity, using a GloMax Discover plate reader, by exciting the sample at $549 \mathrm{~nm}$ and collecting the emission signal at $575 \mathrm{~nm}$. Data from independent experiments were averaged and the effect of CBD/FCCP was expressed as percentage of TMRE signal in comparison to control.

\section{EYFP-Cyt c transfection}

DH5 $\alpha$ competent bacteria (18258012, Thermo Fisher Scientific) were transformed by heat shock and EYFP-Cyt$\mathrm{C}$ construct ${ }^{42}$ was added and incubated for $14 \mathrm{~h}$ at $37^{\circ} \mathrm{C}$ in LB agar (22700025, Thermo Fisher Scientific), supplemented with $100 \mu \mathrm{g} / \mu \mathrm{L}$ of ampicillin (11593027, Thermo Fisher Scientific). Colonies were selected and transferred to supplemented media for further incubation during $14 \mathrm{~h}$ for bacterial growth. Plasmid DNA was purified by NucleoBond XtraMidi (740410.10, Macherey-Nagel) kit, and DNA purity and concentration were evaluated spectrophotometrically by absorption at $260 / 280 \mathrm{~nm}$. For transfection, $10^{5}$ Jurkat cells were starved in Optimem reduced media for $12 \mathrm{~h}$, then exposed to complexes composed by lipofectamine 3000 (L3000015, Thermo Fisher Scientific) and plasmidic DNA (500 ng) and centrifuged $(400 \times g)$ for $30 \mathrm{~min}$ to promote interaction. Transfected cells were incubated at $37^{\circ} \mathrm{C}$, with $5 \% \mathrm{CO}_{2}$ overnight, whereas FBS (10\%) was added at the next day. Protein expression was monitored, and experiments were performed $12 \mathrm{~h}$ after transfection. Images were acquired using a confocal microscope (LSM 700, Carl Zeiss) equipped with $\times 40 / \times 63$ oil-immersion objectives.

\section{Cyt-C release microscopic assay}

Jurkat cells transfected with EYFP-Cyt-C (Ex/Em max $=514 / 526 \mathrm{~nm})$ were labeled with TMRE $(200 \mathrm{nM}$, $30 \mathrm{~min}$ ) to confirm mitochondrial EYFP-Cyt-C localization. EYFP-Cyt-C expression and distribution were evaluated in Jurkat cells $12 \mathrm{~h}$ after transfection by confocal microscopy. The effect of CBD $(30 \mu \mathrm{M})$ was monitored in transfected cells incubated for indicated period with the drug. To evaluate the effects of CsA and Ru360, cells were preincubated with one of these drugs for $10 \mathrm{~min}$, followed by treatment with CBD. For data acquisition, cells were placed in home-made coverslips-bottomed chambers. The images were acquired using a confocal microscope (LSM 700 , Carl Zeiss), equipped with $\times 40 / \times 63$ oil-immersion objectives.

\section{ROS production}

To evaluate ROS production, 2',7'-Dichlorofluorescin diacetate (DCFDA, D6883, Merck) was used following manufacturer's recommendations. Jurkat cells $\left(10^{6} / \mathrm{mL}\right)$ 
were loaded with permeable DCFDA $(2 \mu \mathrm{M})$ for $30 \mathrm{~min}$ in HBSS. After this, cells were washed to remove extracellular dye. Cells were resuspended in RPMI1640 medium and allowed to recover and to hydrolyze the AM groups, producing the insoluble form. Culture media was removed, and cells were resuspended in HBSS and treated either with PMA $(1 \mu \mathrm{M}, \mathrm{P} 8139$, Merck) as a positive control or with CBD $(10$ and $30 \mu \mathrm{M})$. For data acquisition, cells were placed in home-made coverslips-bottomed chambers. Images were acquired by confocal microscopy (LSM 700, Carl Zeiss), equipped with $\times 40 / \times 63$ oil-immersion objectives and analyzed by ZEN imaging software.

\section{Caspase $3 / 9$ assay}

Caspase 3/9 colorimetric assays (K106/119, BioVision) were used following manufacturer's recommendations. Jurkat cells were grown in the presence of vehicle, staurosporine (positive control) or CBD during $12 \mathrm{~h}$. After this period, $10^{6}$ cells from each sample were washed, resuspended in lysis buffer and incubated over $10 \mathrm{~min}$ on ice. Then samples were centrifuged $(10,000 \times g, 15 \mathrm{~min})$ and supernatants (cytosolic fraction) were transferred into new tubes. For caspase activity assays, $100 \mu \mathrm{g}$ of protein (as estimated by BCA protein quantification kit, Merck) from every sample were mixed with $50 \mu \mathrm{L}$ of reaction buffer (containing $10 \mathrm{mM} \mathrm{DTT}$ ) and $5 \mu \mathrm{L}(4 \mathrm{mM})$ of the caspases' substrates (DEVD- $p$ NA for caspase 3, LEHD$p$ NA for caspase 9). Mixtures were incubated for $2 \mathrm{~h}$ at $37^{\circ} \mathrm{C}$ and placed into a 96-well plate. Absorbance was measured at $405 \mathrm{~nm}$, using a GloMax Discover plate reader. Data from three independent experiments were averaged and normalized in relation to non-treated cells, yielding fold increase in caspase activity.

\section{Transmission electron microscopy}

Jurkat cells were treated with CBD $(30 \mu \mathrm{M})$ for $2 \mathrm{~h}$. Next, control or treated cells were centrifuged $(400 \times g)$, supernatants were discarded and the pellets were fixed with $2.5 \%$ glutaraldehyde and post-fixed in $1 \% \mathrm{OsO}_{4}$ and $0.8 \% \mathrm{~K}_{4} \mathrm{Fe}(\mathrm{CN})_{6} \cdot 3 \mathrm{H}_{2} \mathrm{O}$, and $5 \mathrm{mM} \mathrm{Ca}^{2+}$. Post-fixed cells were dehydrated in acetone and embedded in Epon. Ultrathin sections were stained with uranyl acetate and lead citrate and examined under a JEOL JEM 12000 EII transmission electron microscope at the Unidad de Imagenología, Instituto de Fisiología Celular (IFC), UNAM, Mexico City.

\section{CEPIA3mt transfection}

DH5 $\alpha$ competent bacteria (18258012, Thermo Fisher Scientific) were transformed by heat shock and CEPIA3mt/pCMV construct (58219, Addgene) was added ${ }^{27}$. Samples were incubated for $14 \mathrm{~h}$ at $37^{\circ} \mathrm{C}$ in LB agar (22700025, Thermo Fisher Scientific), supplemented with $100 \mu \mathrm{g} / \mu \mathrm{l}$ of ampicillin (11593027, Gibco). Colonies were selected and transferred to supplemented media for further incubation during $14 \mathrm{~h}$ for bacterial growth. Plasmid DNA was purified by NucleoBond XtraMidi (740410.10, Macherey-Nagel) kit and purity and DNA concentration were determined by spectrophotometry (absorption at $260 / 280 \mathrm{~nm}$ ). For the transfection, $10^{5}$ Jurkat cells were starved in Optimem reduced media over $12 \mathrm{~h}$, collected, exposed to complexes of lipofectamine 3000 (L3000015, Thermo Fisher Scientific) and plasmidic DNA $(1 \mu \mathrm{g})$, and centrifuged $(400 \times g)$ for $30 \mathrm{~min}$ to promote interaction. Cells were incubated at $37^{\circ} \mathrm{C}$ with $5 \%$ $\mathrm{CO}_{2}$ overnight, whereas FBS $(10 \%)$ was added at the next day. Protein expression was monitored, and experiments were performed $24 \mathrm{~h}$ after transfection. For confocal imaging, cells were placed in home-made coverslips-bottomed chambers. Images were acquired using a confocal microscope (LSM 700, Carl Zeiss) equipped with $\times 40 / \times 63$ oil-immersion objectives.

\section{Determination of the intracellular free $\mathrm{Ca}^{2+}$ concentration}

For free $\left[\mathrm{Ca}^{2+}\right]_{\mathrm{i}}$ measurements, cells were loaded with ratiometric $\mathrm{Ca}^{2+}$ indicator Fura-2 (F1201, Thermo Fisher Scientific). Cells were twice washed with PBS and resuspended in a loading solution (HBSS, $0.01 \%$ pluronic acid, $2 \mu \mathrm{M}$ Fura-2/AM), incubated for $30 \mathrm{~min}$ at room temperature protected from light, washed, and resuspended in HBSS. Changes in fluorescence were recorded with a F7000 spectrophotometer (Hitachi High-Technologies). Measurements were realized in quartz cuvettes, containing $1.5 \times 10^{6}$ cells $/ \mathrm{mL}$. Loaded cells were excited alternately at $340 / 380 \mathrm{~nm}$ and the fluorescence emission was collected every $2 \mathrm{~s}$ at $510 \mathrm{~nm}$. Fluorescence was recorded by means of the FL-solutions software. Maximum and minimum free $\left[\mathrm{Ca}^{2+}\right]$ levels were determined at the end of each experiment by adding $0.3 \%$ Triton X-100 and consequent addition of EGTA to a final concentration of $35 \mathrm{mM}$, respectively. Free $\left[\mathrm{Ca}^{2+}\right]_{\mathrm{i}}$ was calculated by using the following equation:

$$
\left[\mathrm{Ca}^{2+}\right]_{\mathrm{i}}=K_{\mathrm{d}}\left(R-R_{\mathrm{MIN}}\right) /\left(R_{\mathrm{MAX}}-R\right)
$$

where $R$ stays for the ratio of fluorescence intensity upon excitation at 340 to that at $380 \mathrm{~nm}$ and $R_{\mathrm{MIN}}$ and $R_{\mathrm{MAX}}$ correspond to maximal and minimal values of this ratio, determined as described above ${ }^{43}$.

In some experiments $\mathrm{Ca}^{2+}$-free $\mathrm{HBSS}$ was used $(\mathrm{NaCl}$ $143 \mathrm{mM}, \mathrm{KCl} 6 \mathrm{mM}, \mathrm{MgSO}_{4} 5 \mathrm{mM}$, HEPES $20 \mathrm{mM}$, BSA $0.1 \%$, glucose $5 \mathrm{mM}$, EGTA $1 \mathrm{mM}, \mathrm{pH} 7.4, \approx 300 \mathrm{mOsm}$ ).

\section{Mitochondrial $\mathrm{Ca}^{2+}$ measurements}

CEPIA3mt $(\mathrm{Ex} / \mathrm{Em} \max =488 / 510 \mathrm{~nm})$ expression and its mitochondrial localization were confirmed in transfected Jurkat cells, loaded with TMRE, by confocal microscopy (LSM700, Carl Zeiss). For $\left[\mathrm{Ca}^{2+}\right]_{\mathrm{m}}$ 
measurements, $10^{5}$ cells (24 h after transfection) were placed in a quartz cuvette and fluorescence was evaluated by spectrofluorometry, using a F7000 HITACHI spectrofluorometer (FL solution software). Samples were excited at $488 \mathrm{~nm}$ and fluorescence was measured at $510 \mathrm{~nm} .\left[\mathrm{Ca}^{2+}\right]_{\mathrm{m}}$ was evaluated as fluorescence intensity in relation to the initial fluorescence intensity (F/F0).

\section{Mitochondria isolation}

Mitochondria were isolated as reported earlier ${ }^{39}$, with some modifications. Jurkat cells were harvested and centrifuged $(400 \times g)$ at $4{ }^{\circ} \mathrm{C}$ for $10 \mathrm{~min}$, washed twice with PBS (pH 7.4) and resuspended in 10x of volume of isolation buffer (IB, HEPES-KOH $20 \mathrm{mM}$, PMSF $1 \mathrm{mM}$, sucrose $250 \mathrm{mM}$, mercaptoethanol $1 \mathrm{mM}$, EGTA $1 \mathrm{mM}$, EDTA $1 \mathrm{mM}, \mathrm{MgCl}_{2} 1.5 \mathrm{mM}, \mathrm{KCl} 10 \mathrm{mM}$ ). Cells were incubated on ice for $10 \mathrm{~min}$ and homogenized with a Dounce homogenizer. Homogenate was then centrifuged at $650 \times g$ for $10 \mathrm{~min}$ at $4{ }^{\circ} \mathrm{C}$, pellet, containing nuclei, was discarded and the supernatant was collected for a further $12500 \times g$ centrifugation for $30 \mathrm{~min}$ at $4{ }^{\circ} \mathrm{C}$. Pellet containing the heavy membrane fractions (HMF) was collected and the supernatant was discarded. HMF were washed with IB and resuspended in isotonic sucrose buffer (sucrose $250 \mathrm{mM}$, EDTA $1 \mathrm{mM}$, Tris- $\mathrm{HCl} \mathrm{pH} 7.4$ $10 \mathrm{mM}$ ). Homogenate was placed in a discontinuous sucrose gradient (sucrose 1/1.5 M, EDTA $1 \mathrm{mM}$, Tris- $\mathrm{HCl}$ $\mathrm{pH} 7.410 \mathrm{mM}$ ) and centrifuged for $25 \mathrm{~min}$ at $60,000 \times g$, $4{ }^{\circ} \mathrm{C}$. Mitochondria were collected from the interphase, washed and resuspended in the experimental buffer $(\mathrm{KCl}$ $125 \mathrm{mM}, \mathrm{KH}_{2} \mathrm{PO}_{4} 1 \mathrm{mM}$, Tris- $\mathrm{HCl} 10 \mathrm{mM}$, glutamate $5 \mathrm{mM}$, malate $2.5 \mathrm{mM}$, EGTA $1 \mathrm{mM}, \mathrm{CaCl}_{2} 0.7 \mathrm{mM}$ ). Isolated mitochondria were suspended in the lysis buffer (Nonidet P-40 0.5\% w/v, Tris-HCL $50 \mathrm{mM}, \mathrm{NaCl}$ $150 \mathrm{mM}$, EDTA $1 \mathrm{mM}$, and PMSM $1 \mathrm{mM}$ ) for $1 \mathrm{~h}$ and centrifuged at $15000 \times g$ for $5 \mathrm{~min}$. The supernatant was collected, and isolation yield was estimated by the protein content (BCA quantification assay). Finally, mitochondrial samples, containing $50 \mu \mathrm{g}$ of protein, were used in the experiments. To evaluate the purity and integrity of isolated mitochondria, a small fraction was stained with MtGreen $(200 \mathrm{nM}$, Ex/Em $\max =490 / 510 \mathrm{~nm}$; M7514, Thermo Fisher Scientific) as mitochondrial marker, followed by staining with Rhod $(2 \mu \mathrm{M}, \mathrm{Ex} / \mathrm{Em} \max =552 /$ $581 \mathrm{~nm}$; R1244, Thermo Fisher Scientific) or TMRE $(200 \mathrm{nM}, \quad \mathrm{Ex} / \mathrm{Em} \max =549 / 575 \mathrm{~nm}$; T669, Thermo Fisher Scientific). Samples were acquired by flow cytometry (FACSCantoII, BD Biosciences) and data were analyzed by FlowJo software.

\section{$\mathrm{Ca}^{2+}$ measurement in isolated mitochondria}

Freshly isolated mitochondrial samples $(50 \mu \mathrm{g}$ of protein per sample) were incubated with Rhod2 $(2 \mu \mathrm{M})$ over $30 \mathrm{~min}$, washed by centrifugation $(12500 \times g, 5 \mathrm{~min})$ and resuspended in experimental buffer $(\mathrm{KCl} 125 \mathrm{mM}$, $\mathrm{KH}_{2} \mathrm{PO}_{4} 1 \mathrm{mM}$, TrisHCl $10 \mathrm{mM}$, glutamate $5 \mathrm{mM}$, malate $2.5 \mathrm{mM}$, EGTA $1 \mathrm{mM}, \mathrm{CaCl}_{2} 0.7 \mathrm{mM}$ ). Samples were placed in a quartz cuvette, and fluorescence was evaluated by F7000 spectrophotometer (Hitachi High-Technologies), using excitation at $552 \mathrm{~nm}$ and collecting the fluorescence at $581 \mathrm{~nm}$. Data was recorded using the FLSolution software (Hitachi). $\left[\mathrm{Ca}^{2+}\right]_{\mathrm{m}}$ change was evaluated by taking fluorescence for each acquisition in relation to the initial fluorescence value, F/FO.

\section{Membrane potential measurements on isolated mitochondria}

Isolated mitochondria $(50 \mu \mathrm{g}$ of protein/sample) were stained with TMRE (200 nM; $30 \mathrm{~min})$, treated with CBD $(0-60 \mu \mathrm{M})$ or FCCP $(10 \mu \mathrm{M})$ for $10 \mathrm{~min}$, washed, resuspended in experimental buffer $\left(\mathrm{KCl} 125 \mathrm{mM}, \mathrm{KH}_{2} \mathrm{PO}_{4}\right.$ $1 \mathrm{mM}$, Tris $\mathrm{HCl} 10 \mathrm{mM}$, glutamate $5 \mathrm{mM}$, malate $2.5 \mathrm{mM}$, EGTA $1 \mathrm{mM}, \mathrm{CaCl}_{2} 0.7 \mathrm{mM}$ ) and placed in a 96-well plate. Fluorescence was assayed using a GloMax Discover plate reader, by exciting the sample at $549 \mathrm{~nm}$ and collecting the emission at $575 \mathrm{~nm}$. Data from independent experiments were averaged and the effect of $\mathrm{CBD}$ or FCCP on membrane potential value is defined as \% of TMRE fluorescence with respect to control.

\section{Detection of autophagic flux by LC3 immunoblotting}

During autophagy, the amount of LC3-I decreases and that of LC3-II increases. But at the late phase after autophagolysosome formation LC3-II disappears being degraded by lysosomal proteases. If cells are treated with lysosomal protease inhibitors or with drugs inhibiting autophagosomelysosome fusion, LC3-II degradation is prevented. Thus, LC3-II amount at a certain time point does per se serve a measure of the total autophagic flux. This flux should be more accurately evaluated by comparison of the amount of LC3-II between samples in the presence and absence of lysosomal protease inhibitors or compounds preventing autophagosome-lysosome fusion ${ }^{15,44}$. CQ was shown to prevent autophagosome-lysosome fusion ${ }^{16}$ and was used therefore in the present work.

For Western blot analysis, cells after corresponding treatments $(\mathrm{CQ}, \mathrm{CBD}$, or $\mathrm{CQ}$ and $\mathrm{CBD}$ combination) were harvested and lysed with RIPA buffer (Tris- $\mathrm{HCl}$ $25 \mathrm{mM}$, pH 7.6, NaCl $150 \mathrm{mM}$, EDTA $5 \mathrm{mM}$, NP-40 1\%, sodium deoxycholate $1 \%$, SDS $0.1 \%$ ), supplemented with protease inhibitors (11697498001, Complete, Roche). For protein quantification, BCA Protein Assay Kit (Sigma) was used. For each sample, $15 \mu \mathrm{g} /$ line of protein were loaded on a 15\% SDS-PAGE gel. After electrophoresis $(100 \mathrm{~V}, \sim 2 \mathrm{~h})$, proteins were transferred onto PVDF membranes. Membranes were blocked for 1 hour with 5\% BSA in TBS Tween-20 buffer (TBS-T) and incubated overnight at $4{ }^{\circ} \mathrm{C}$ with anti-human LC3 rabbit antibodies 
(Novus-Biologicals, NB100-2220, dilution 1:3000) and mouse monoclonal anti-human GAPDH antibodies (SCBT, sc-47724, dilution 1:1000) as a loading control. As secondary

antibodies, HRP-conjugated goat anti-rabbit IgG (NovusBiologicals, NBP2-30348H, dilution 1:3000) and HRPconjugated anti-mouse IgGk (SCBT, sc-516102, dilution 1:1000) were used for LC3 and GAPDH, respectively. Membranes were incubated with secondary antibodies over $1 \mathrm{~h}$ at room temperature, followed by incubation with the ECL detection reagent (Bio-Rad, 170-5061). Protein bands were visualized with Bio-Rad Universal Hood II system and analyzed with Image Lab 5.0 software.

\section{Autophagic flux measurement with mCherry-GFP-LC3}

To measure autophagic flux at the single cell level, Jurkat cells, stably expressing tandem mCherry-GFP-LC3, were used ${ }^{45}$. Cells were cultured in the presence of CBD, CQ or their combination for 2, 4, and $24 \mathrm{~h}$. After these periods, cells were collected by centrifugation $(100 \times g)$, suspended in PBS and placed in a in home-made coverslips-bottomed chambers for microscopy imaging. Double positive mCherry + /GFP + puncta represented autophagosomes, whereas fusion with the lysosome (autophagolysosomes) caused quenching of the $\mathrm{pH}$-sensitive GFP, resulting in appearance of mCherry + GFP- puncta. CQ prevents GFP quenching by inhibiting autophagosomelysosome fusion ${ }^{16}$. Samples were analyzed by confocal microscopy (LSM700, Carl Zeiss). Alternatively, custommade confocal microscope (Solamere Technology Group, Salt Lake City, USA) based on a Yakogawa spindisk confocal scan head (CSUX1M1, Yokogawa Electronic Co., Tokio, Japan), equipped with solid state Coherent Obis lasers $(405,488,561$ and $640 \mathrm{~nm})$ was used. Autophagy flux was evaluated by counting red (mCherry + ) and green $(\mathrm{GFP}+)$ puncta $\left(0.5-3 \mu \mathrm{m}^{2}\right)$ in the cells. Data analysis was performed using "Particle analysis" tool of ImageJ software, as reported by others ${ }^{46-48}$. Three fields for each condition (10-20 cells/ field) in at least three independent experiments were analyzed. Data are presented as mean of LC3 puncta/ cell or as mean of mCherry/GFP ratio.

\section{Protein-ligand docking}

To explore binding sites for CBD within human VDAC1 channel, molecular docking analysis was performed, using Molegro virtual docker 6.0 software. Chemical structure of CBD was obtained from Pubchem (NIH, 644019), whereas hVDAC1 channel structure was downloaded from the protein data bank (PDB, 2JK4). For the beginning, three main cavities for hVDAC1 were defined and explored as possible CBD-interacting sites. MolDock Optimizer was selected as a search algorithm, 20 runs (number of times that the docking is repeated for each ligand) was chosen, and 1000 ligand binding conformations were established.
From them, the best 5, based on their docking score (MolDock Score), were selected for each cavity. For all 15 selected binding conformations the contribution of each participating residue in the CBD binding was evaluated (Ligand map > Ligand Energy Inspector). Finally, basing on Total energy/MolDock Score, the best binding conformation was revealed and plotted by creating backbone visualization in the workspace.

\begin{abstract}
Acknowledgements
This study was funded by CONACyT grants 220793 to I.P., FC2015/1-140 to O.D., and PAPIIT IG200119 (DGAPA-UNAM) to A.H.C.; doctoral fellowships (M.O. A., L.T.L. and J.SV.R). We thank Dr. Boehning and Dr. Methner for providing EYFP-Cyt C and CEPIA3mt plasmids, Dr. Thorburn for gifting mCherry-GFP-LC3 expressing Jurkat cells, Dr. Rincón-Heredia and Dr. Díaz for sample preparation and data acquisition by TEM, and Dr. Gómez and Mr. Reyes for their assistance in the docking simulations. Technical assistance of L. Liñan-Rico and M. Flores (University of Colima), Dr. Picones, Dr. Loza, O. Lara, and L. Durán (National Laboratory of Channelopathies) is appreciated.
\end{abstract}

Conflict of interest

The authors declare that they have no conflict of interest.

\section{Publisher's note}

Springer Nature remains neutral with regard to jurisdictional claims in published maps and institutional affiliations.

Supplementary Information accompanies this paper at (https://doi.org/ 10.1038/s41419-019-2024-0).

Received: 21 May 2019 Revised: 22 August 2019 Accepted: 24 September 2019

Published online: 14 October 2019

\section{References}

1. Nguyen, $\mathrm{K}$. et al. Factors influencing survival after relapse from acute lymphoblastic leukemia: a Children's Oncology Group Study. Leukemia 22, 2142-2150 (2008).

2. Bassan, R. \& Hoelzer, D. Modern therapy of acute lymphoblastic leukemia. J. Clin. Oncol. 29, 532-543 (2011).

3. Pui, C. H. \& Evans, W. E. A 50-year journey to cure childhood acute lymphoblastic leukemia. Semin. Hematol. 50, 185-196 (2013).

4. Raetz, E. A. \& Teachey, D. T. T-cell acute lymphoblastic leukemia. Hematol. Am. Soc. Hematol. Educ. Program. 2016, 580-588 (2016).

5. Pui, C. H., Yang, J. J., Bhakta, N. \& Galindo, C. Global efforts toward the cure of childhood acute lymphoblastic leukaemia. Lancet Child Adolesc. Health 2 440-454 (2018).

6. Solinas, M, Cinquina, V. \& Parolaro, D. Cannabidiol and Cancer - An Overview of the Preclinical Data, Molecular Considerations and Evolving Surgical Management Issues in the Treatment of Patients with a Brain Tumor. Ch. 8. (IntechOpen, London, 2015).

7. Ladin, D. A., Soliman, E., Griffin, L. \& Van Dross, R. Preclinical and clinical assessment of cannabinoids as anti-cancer agents. Front. Pharmacol. 7, 361 (2016).

8. Russo, E. B. Cannabidiol claims and misconceptions. Trends Pharmacol. Sci. 38, 198-201 (2017).

9. Massi, P., Solinas, M., Cinquina, V. \& Parolaro, D. Cannabidiol as potential anticancer drug. Br. J. Clin. Pharmacol. 75, 303-312 (2013).

10. Yadav, B. D. et al. Heterogeneity in mechanism of emergent resistant in pediatric T-cell acute lymphoblastic leukemia. Oncotarget 7, 58728-58742 (2016).

11. Pitt, L. A. et al. CXCL12-producing vascular endothelial niches control acute $T$ cell leukemia maintenance. Cancer Cell 27, 755-768 (2015).

12. Passaro, D. et al. CXCR4 is required for leukemia-initiating cell activity in T cell acute Iymphoblastic leukemia. Cancer Cell 27, 769-779 (2015). 
13. Galluzzi, L., Pietrocola, F., Levine, B. \& Kroemer, G. Metabolic control of autophagy. Cell 159, 1263-1376 (2014).

14. Shrivastava, A., Kuzontkoski, P. M., Groopman, J. E. \& Prasad, A. Cannabidiol induces programmed cell death in breast cancer cells by coordinating the cross-talk between apoptosis and autophagy. Mol. Cancer Ther. 10, 1161-1172 (2011).

15. Mizushima, N. \& Yoshimori, T. How to interpret LC3 immunoblotting. Autophagy 3, 542-545 (2007).

16. Mauthe, M. et al. Chloroquine inhibits autophagic flux by decreasing autophagosome-lysosome fusion. Autophagy 14, 1435-1455 (2018).

17. Pankiv, S. et al. p62/SQSTM1 binds directly to Atg8/LC3 to facilitate degradation of ubiquitinated protein aggregates by autophagy. J. Biol. Chem. 282 24131-24145 (2007)

18. Galluzzi, L. et al. Molecular mechanisms of cell death: recommendations of the Nomenclature Committee on Cell Death 2018. Cell Death Differ. 25, 486-541 (2018).

19. Kalenderoglou, N., Macpherson, T. \& Wright, K. L. Cannabidiol reduces leukemic cell size - but is it important?. Front. Pharmacol. 8, 144 (2017).

20. Giorgio, V., Guo, L., Bassot, C., Petronilli, V. \& Bernardi, P. Calcium and regulation of the mitochondrial permeability transition. Cell Calcium 70, 56-63 (2018).

21. Eskes, R. et al. Bax-induced cytochrome $C$ release from mitochondria is independent of the permeability transition pore but highly dependent on $\mathrm{Mg}^{2+}$ ions. J. Cell Biol. 143, 217-224 (1998).

22. Brustovetsky, N., Brustovetsky, T., Jemmerson, R. \& Dubinsky, J. M. Calciuminduced cytochrome $\mathrm{c}$ release from CNS mitochondria is associated with the permeability transition and rupture of the outer membrane. J. Neurochem. $\mathbf{8 0}$ 207-218 (2002).

23. McKallip, R. J. et al. Cannabidiol-induced apoptosis in human leukemia cells: a novel role of cannabidiol in the regulation of p22phox and Nox4 expression. Mol. Pharmacol. 70, 897-908 (2006).

24. Ligresti, A. et al. Antitumor activity of plant cannabinoids with emphasis on the effect of cannabidiol on human breast carcinoma. J. Pharmacol. Exp. Ther. 318, 1375-1387 (2006)

25. Ryan, D., Drysdale, A. J., Lafourcade, C., Pertwee, R. G. \& Platt, B. Cannabidiol targets mitochondria to regulate intracellular $\mathrm{Ca}^{2+}$ levels. J. Neurosci. 29, 2053-2063 (2009).

26. Orrenius, S., Gogvadze, V. \& Zhivotovsky, B. Calcium and mitochondria in the regulation of cell death. Biochem. Biophys. Res. Commun. 460, 72-81 (2015).

27. Giacomello, M. \& Pellegrini, L. The coming of age of the mitochondria-ER contact: a matter of thickness. Cell Death Differ. 23, 1417-1427 (2016).

28. Suzuki, J. et al. Imaging intraorganellar $\mathrm{Ca}^{2+}$ at subcellular resolution using CEPIA. Nat. Commun. 5, 4153 (2014).

29. Kitamura, Y., Arima, T., Kitayama, Y. \& Nomura, Y. Regulation of $\left[\mathrm{Ca}^{2+}\right]$ i rise activated by doxepin-sensitive $\mathrm{H1}$-histamine receptors in Jurkat cells, cloned human T lymphocytes. Gen. Pharmacol. 27, 285-291 (1996).

30. Rimmerman, $\mathrm{N}$. et al. Direct modulation of the outer mitochondrial membrane channel, voltage-dependent anion channel 1 (VDAC1) by cannabidiol: a novel mechanism for cannabinoid-induced cell death. Cell Death Dis. 4, e949 (2013).

31. Tan, W. \& Colombini, M. VDAC closure increases calcium ion flux. Biochim. Biophys. Acta 1768, 2510-2505 (2007)

32. Rizzuto, R., De Stefani, D., Raffaello, A. \& Mammucari, C. Mitochondria as sensors and regulators of calcium signaling. Nat. Rev. Mol. Cell Biol. 13, 566-578 (2012).

33. Szabo, I. \& Zoratti, M. Mitochondrial channels: ion fluxes and more. Physiol. Rev. 94, 519-608 (2014)

34. Szabadkai, G. et al. Chaperone-mediated coupling of endoplasmic reticulum and mitochondrial Ca ${ }^{2+}$ channels. J. Cell Biol. 175, 901-911 (2006).

35. De Stefani, D., Patron, M. \& Rizzuto, R. Structure and function of the mitochondrial calcium uniporter complex. Biochim. Biophys. Acta 1853, 2006-2011 (2015).

36. Colombini, M. Mitochondrial outer membrane channels. Chem. Rev. 112, 6373-6387 (2012).

37. Rezaul, K., Wu, L., Mayva, V., Hwang, S. \& Han, D. A systematic characterization of mitochondrial proteome from human T leukemia cells. Mol. Cell Proteom. 4, 169-181 (2005).

38. Jiang, $\mathrm{N}$. et al. Identification of prognosis protein biomarkers in childhood acute lymphoblastic leukemia (ALL). J. Proteom. 74, 843-857 (2011).

39. Prezma, T. et al. VDAC1-based peptides: novel pro-apoptotic agents and potential therapeutics or B-cell chronic lymphocytic leukemia. Cell Death Dis. 4 e809 (2013)

40. Bonora, M. \& Pinton, P. The mitocondrial permeability transition pore and cancer: molecular mechanisms involved in cell death. Front. Oncol. 4, 302 (2014).

41. Denton, R. Regulation of mitochondrial dehydrogenases by calcium ions. Biochim. Biophys. Acta 1787, 1309-1316 (2009).

42. Boehning, D. et al. Cytochrome $\mathrm{c}$ binds to inositol $(1,4,5)$ trisphosphate receptors, amplifying calcium-dependent apoptosis. Nat. Cell Biol. $\mathbf{5}$ 1051-1061 (2003)

43. Grynkiewicz, G., Poenie, M. \& Tsien, R. Y. A new generation of $\mathrm{Ca}^{2+}$ indicators with greatly improved fluorescence properties. J. Biol. Chem. 260, 3440-3450 (1985).

44. Klionsky, D. J. et al. Guidelines for the use and interpretation of assays for monitoring autophagy. Autophagy 12, 443 (2016).

45. Gump, J. M. \& Thorburn, A. Sorting cells for basal and induced autophagic flux by quantitative ratiometric flow cytometry. Autophagy 10, 1327-1334 (2014).

46. Zhou, C. et al. Monitoring autophagic flux by an improved tandem fluorescent-tagged LC3 (mTagRFP-mWasabi-LC3) reveals that high-dose rapamycin impairs autophagic flux in cancer cells. Autophagy 8, 1215-1226 (2012).

47. Castillo, K., Valenzuela, V., Oñate, M. \& Hetz, C. A molecular reporter for monitoring autophagic flux in nervous system in vivo. Methods Enzymol. $\mathbf{5 8 8}$ 109-131 (2017).

48. Runwal, G. et al. LC3-positive structures are prominent in autophagy-deficient cells. Sci. Rep. 9, 10147 (2019). 